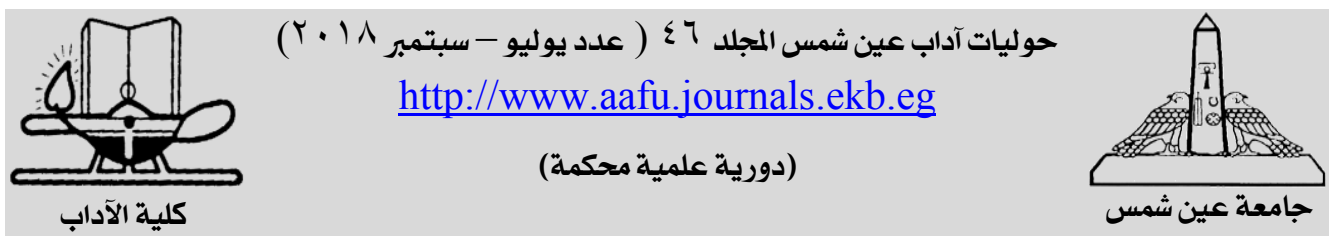

الاعتداءات البورهية المتكررة على الأقلية المسلمة " الروهينجا" في بورهما

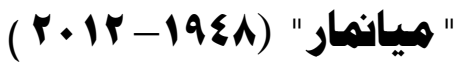

$$
\begin{aligned}
& \text { * ميسون منصور عبيدات }
\end{aligned}
$$

أستاذ مشارك، قسم التاريخ، كلية العلوم الاجتماعية، جامعة مؤتة، الكرك، الأردن

untivingl|

يهدف البحث إلى تعريف القارئ بأهم الاعتداءات و الانتهاكات بحق الأقلية

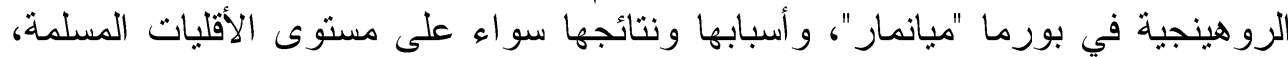

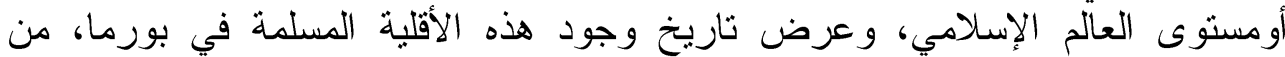

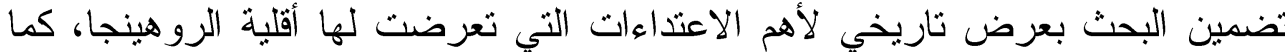

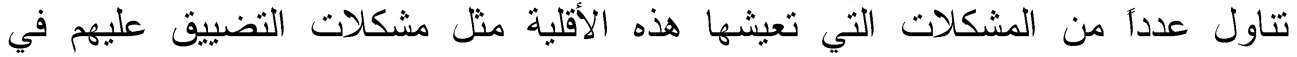

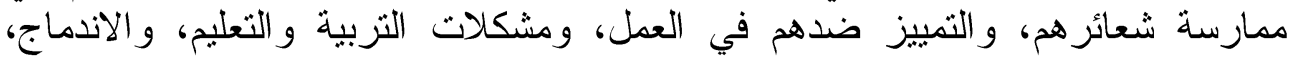

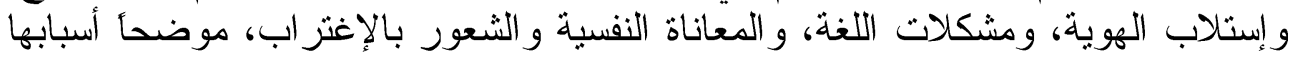

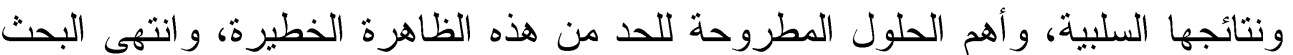

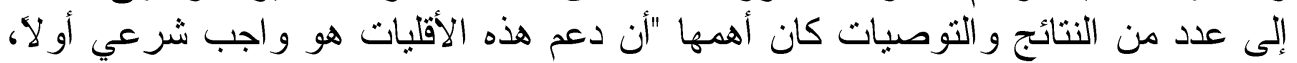

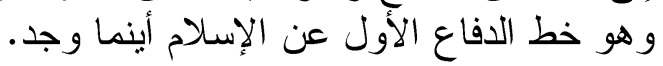
الكلمات الافتتاحية: الرو هينجا، بورما، مبانمار ، البوذيين. 


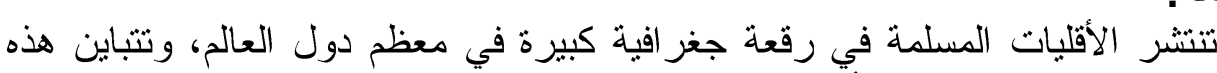

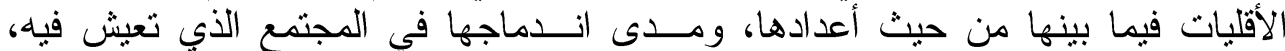

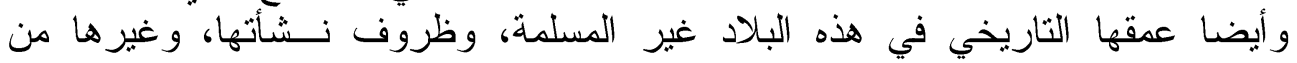

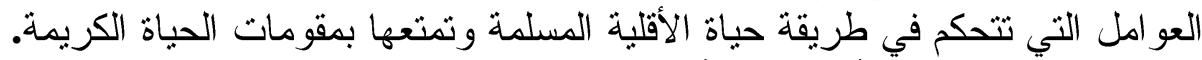

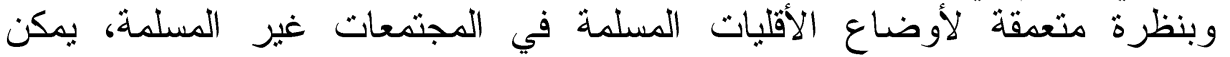

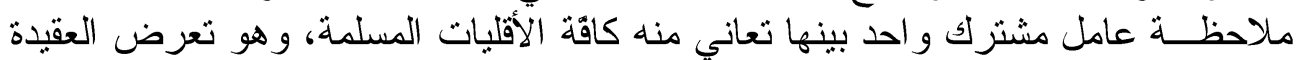

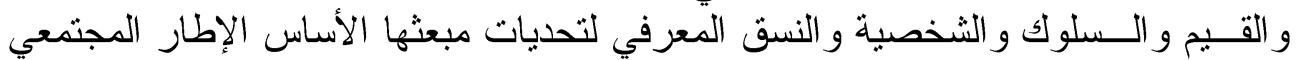

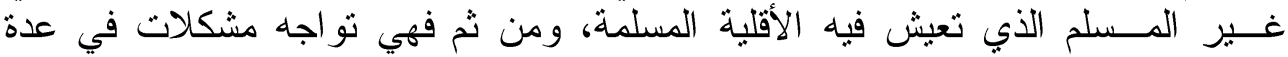

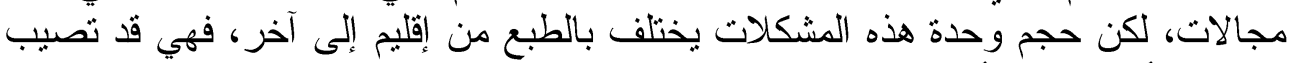

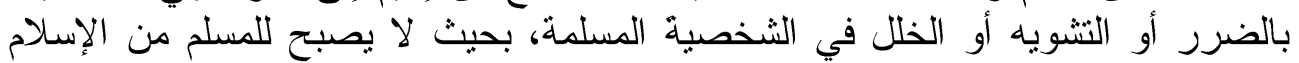

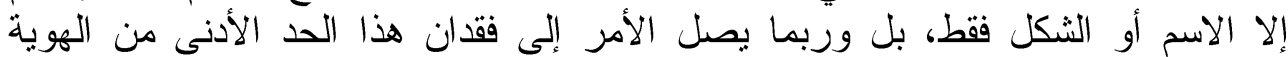

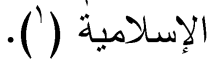

فعلى سبيل المثال، يشكل المسلمون في جنوب شرق آسيا أكبر الأقليات الإسلامية

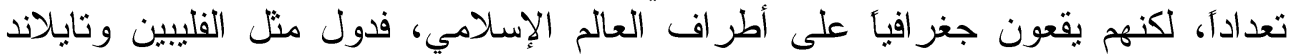

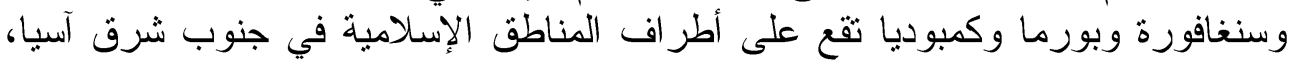

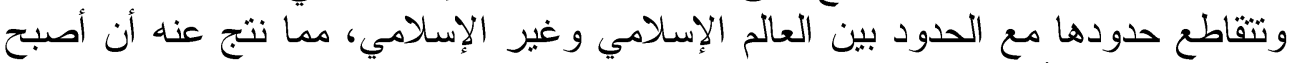

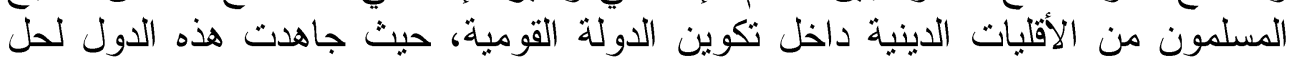

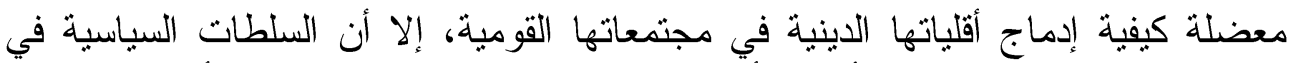

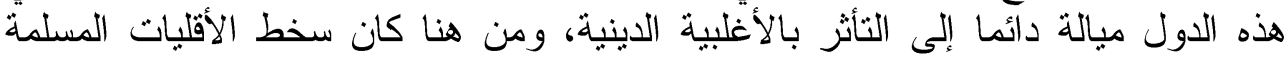

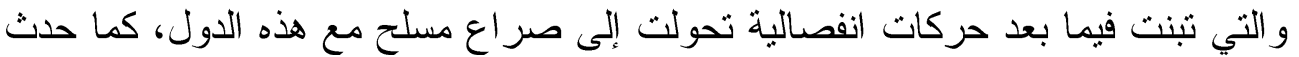

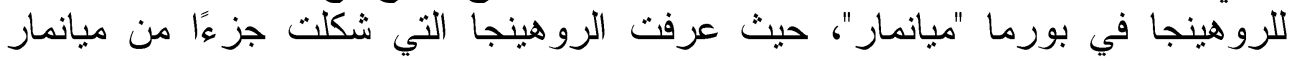

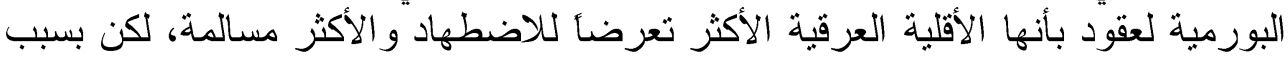

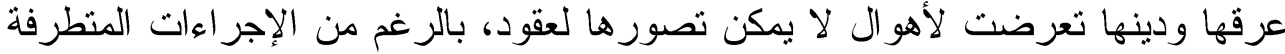

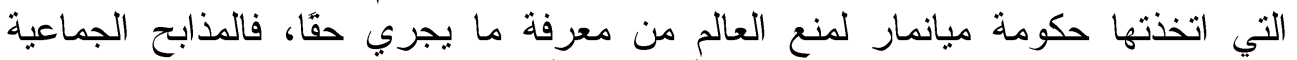

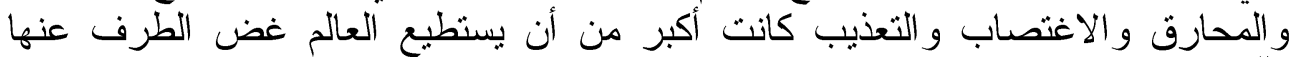

وفي بورما أصبحت حركة (979) رمزأ لتبار بوذي يسعى إلى عزل وتهجير المسلمين

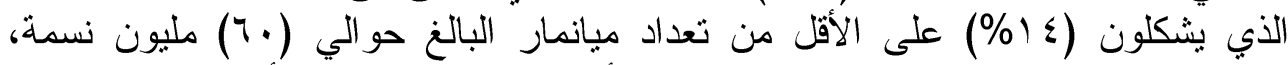

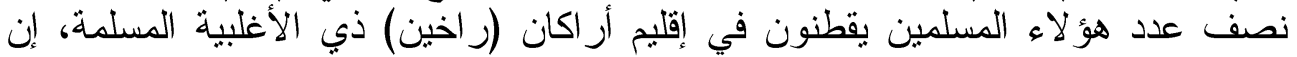

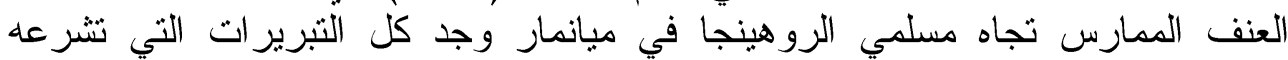

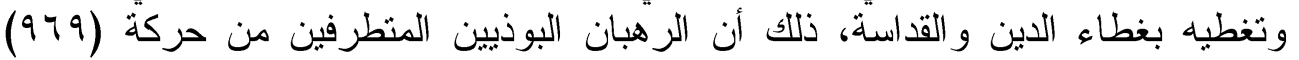

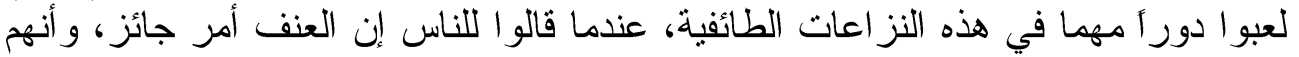

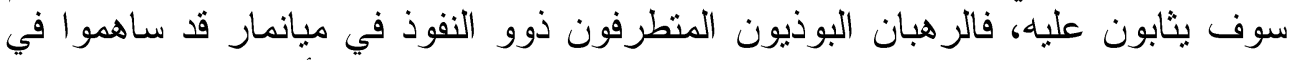

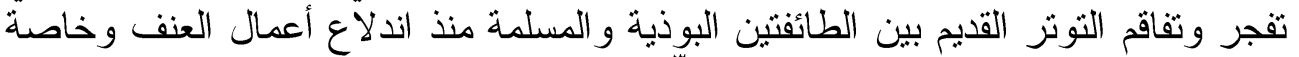

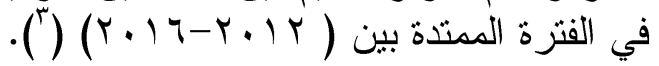

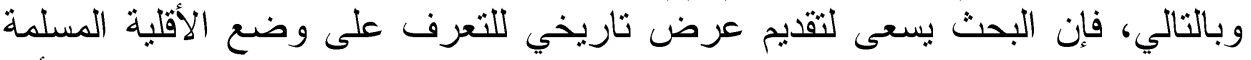

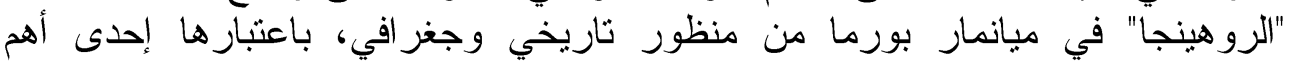

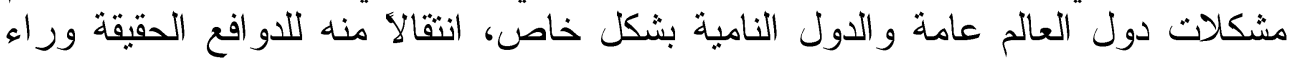

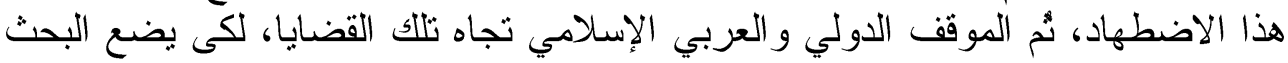


في النهاية تصور آلمستقبل الأقليات المُسلمة في تلك المنطقة المنسية من العالم.

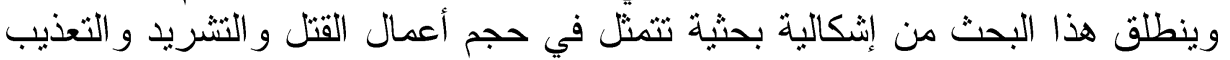

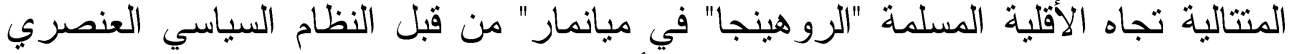

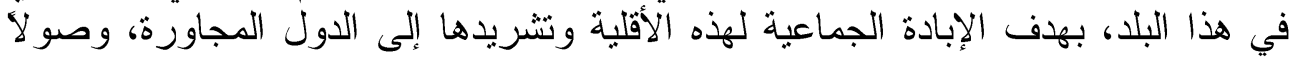

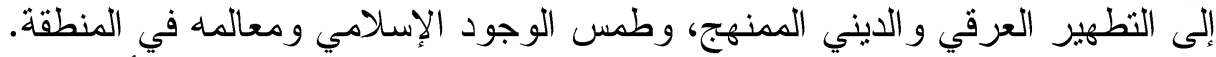

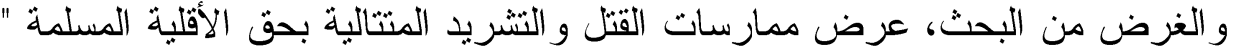

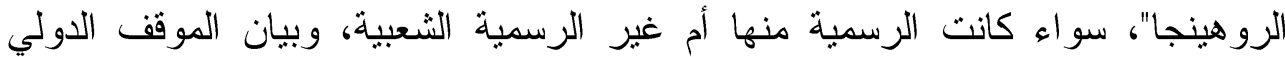

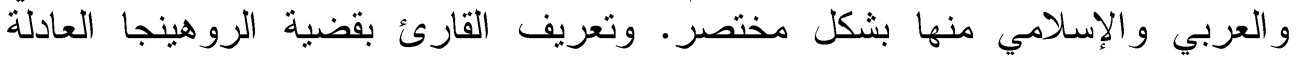

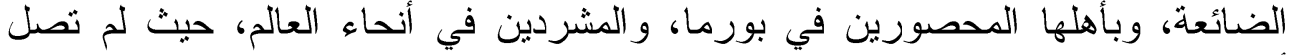

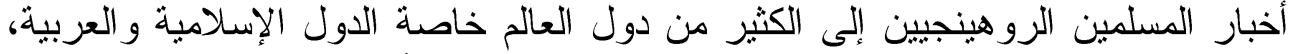

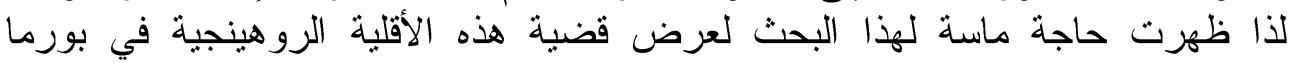

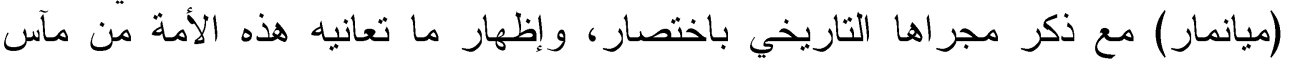

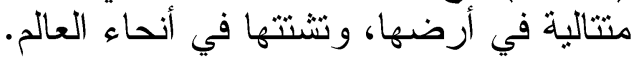

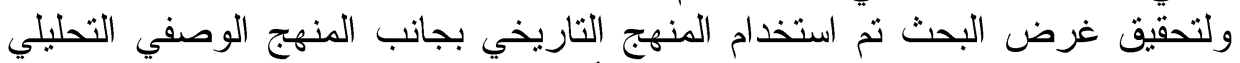

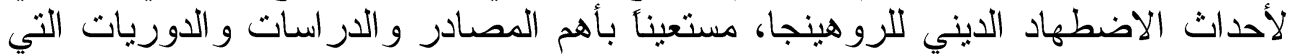

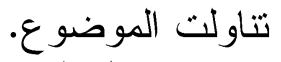

و اشتمل البحث على مقدمة، وثناثثة مباحث، وخاتمة.

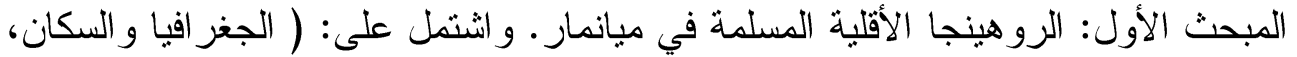

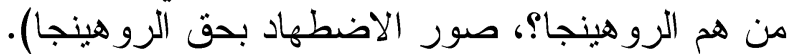

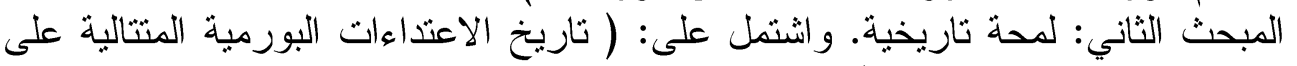
الرو هينجا، مقاومة الاضطهاد). المبحث الثالث: المو اقف الدولية و العربية و الإسلامية تجاه اضطهاد الروهينجا في ميانمار.

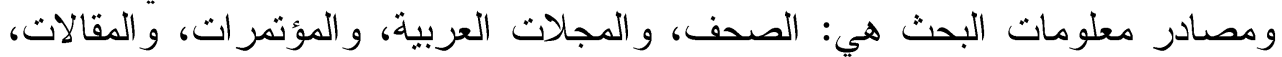
وشبكة الانترنت، وبعض الكتب التي تتاولت الأقليات المسلمة في دول شرق آسبا و العالم

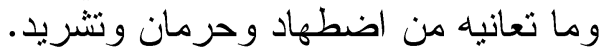
هذا وقد تصدت منظمات دولية وعربية وإسلامية لأعمال القتل و الحرق و التشريد

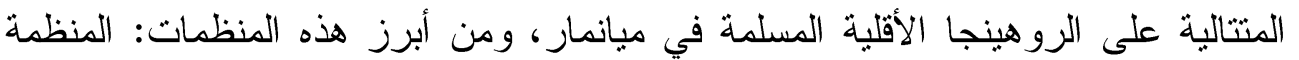

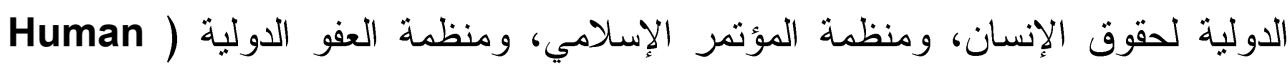
Rights Watch

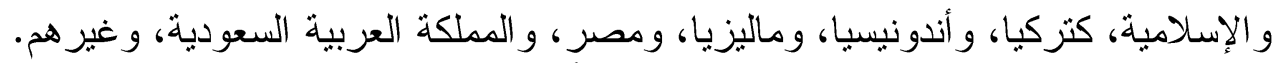

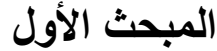

"الروهينجا" الأقلية المسلمة في ( ميانمار البورمية)

تقع جمهورية اتحاد ميانمار البورية البان في في جنوب شرث آسيا، و انفصلت في الأول المطلب الأول: الجغرافيا والسكان:

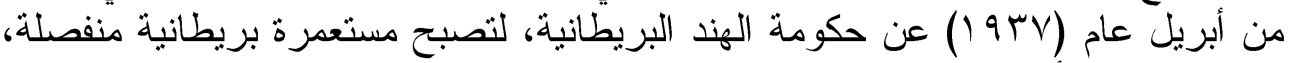

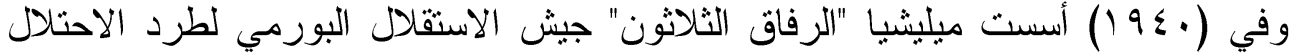
البريطاني، وقد نال قادة هذا الجيش التنريب العسكري في اليابان، وعادوا مع الغزو الغزو 


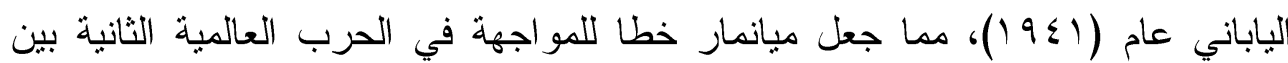

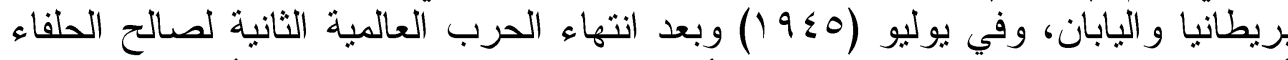

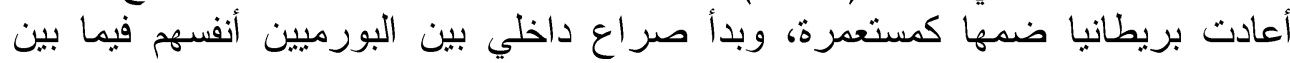

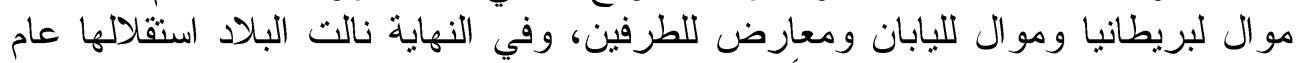

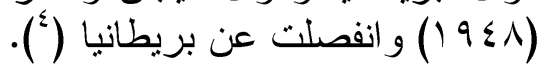
يختلف سكان بورما من حيث النزكيب العرقي و اللغوي، فيتحدث أغلب سكانها

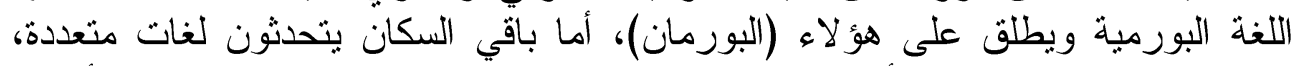

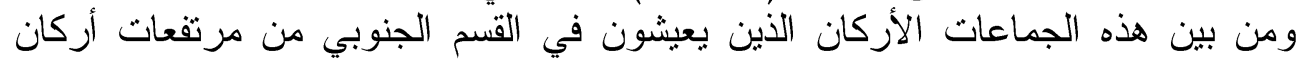

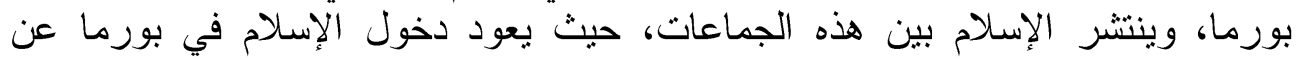

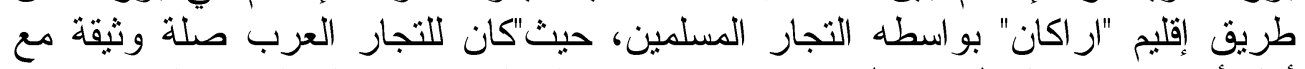

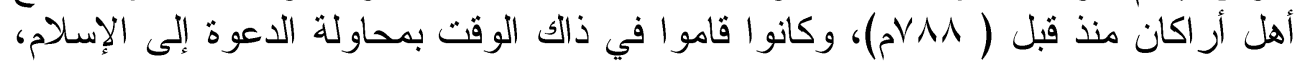

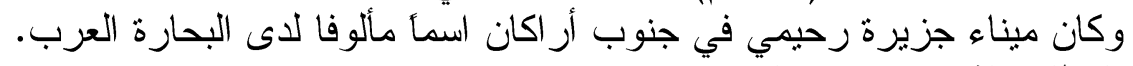

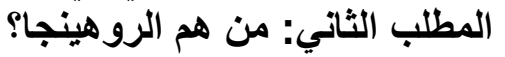

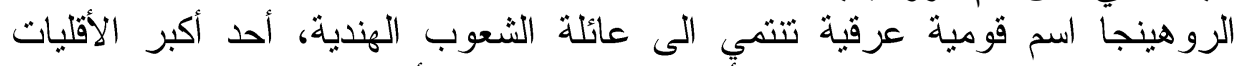

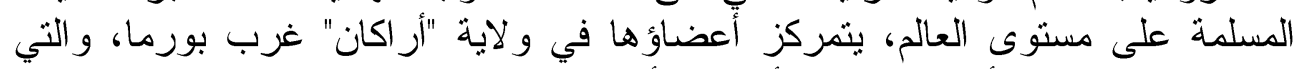

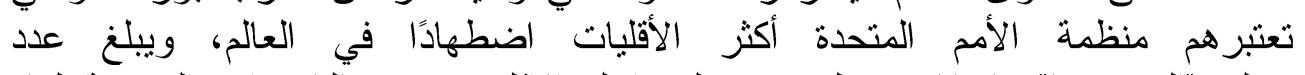

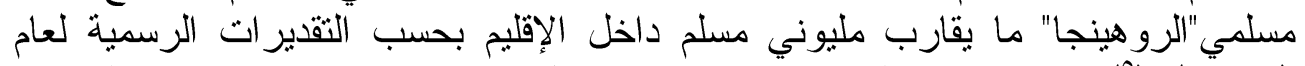
(T)

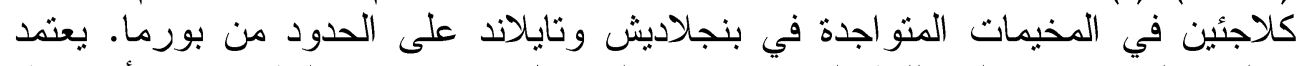

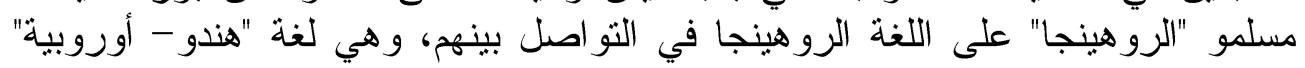

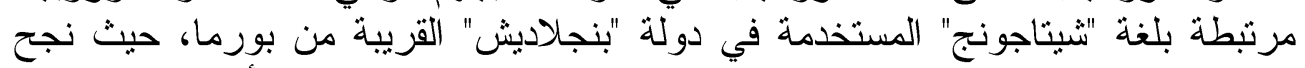

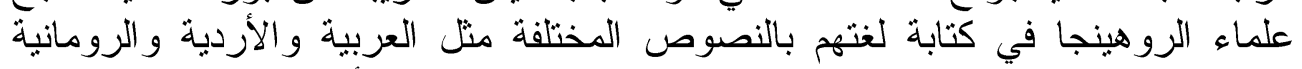

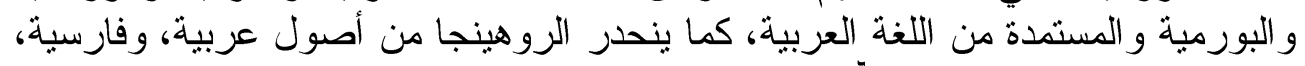

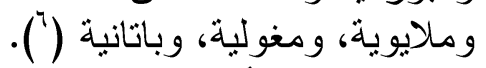

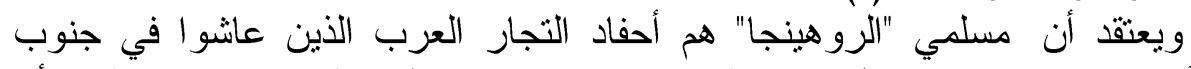

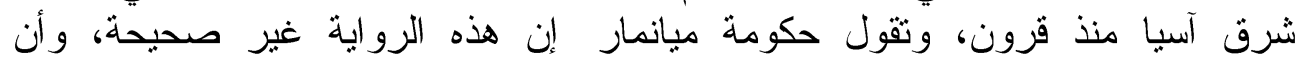

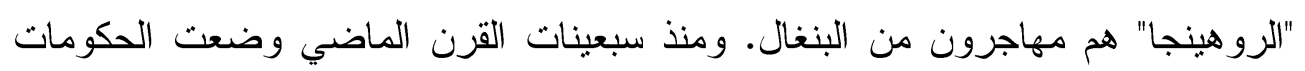

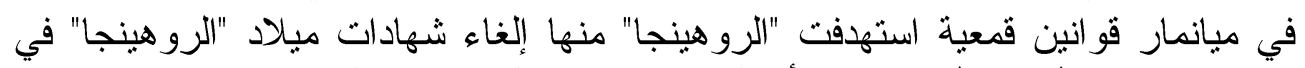

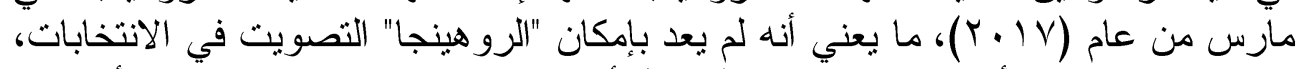

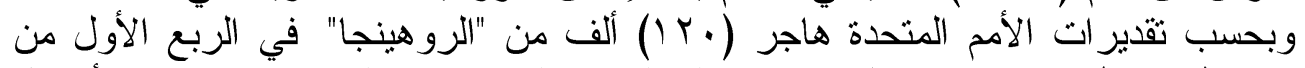

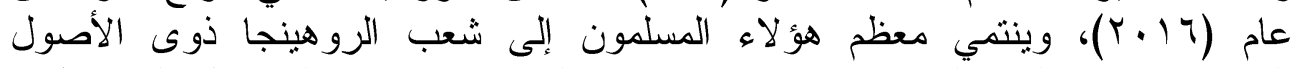

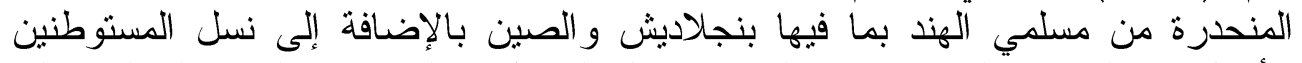

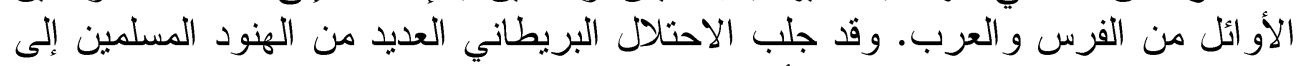

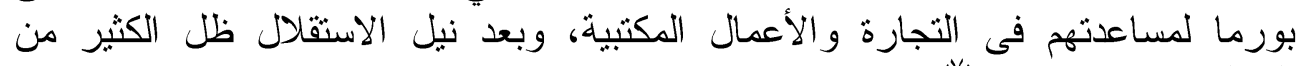
المسلمين في مو اقعهم ( ال). وصل الإسلام إلى إقليم أر اكان في القرن السابع الميلادي، وكون شعب الروهينجا

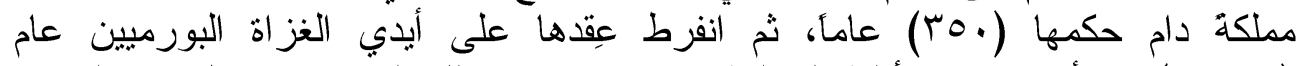

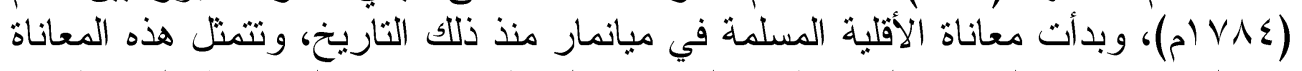

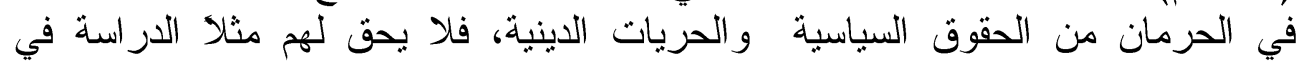


المدارس و الجامعات الحكومية، كما تمــت مصادرة الأوقاف الإسلامية ومن أشهرها

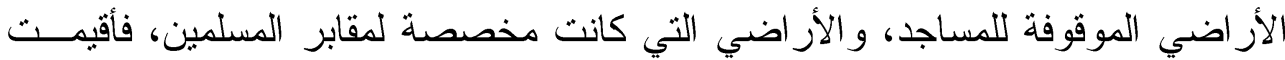

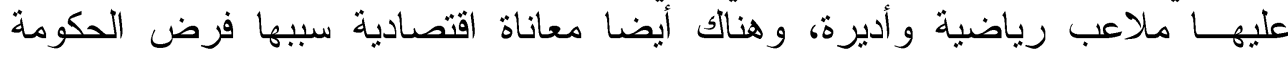

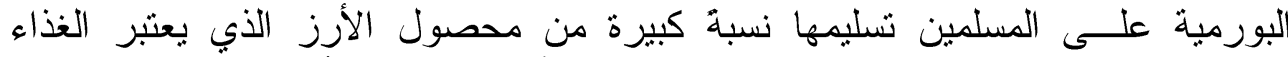

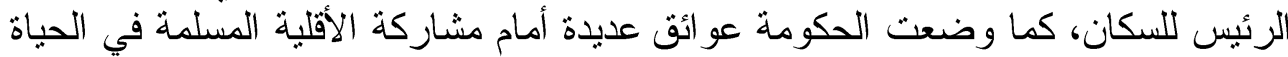

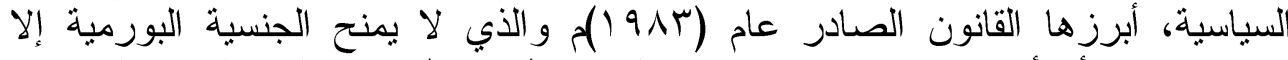

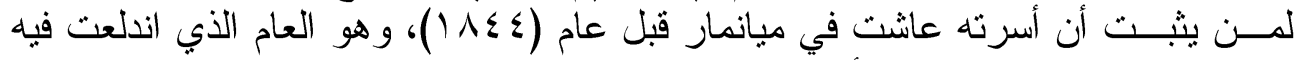

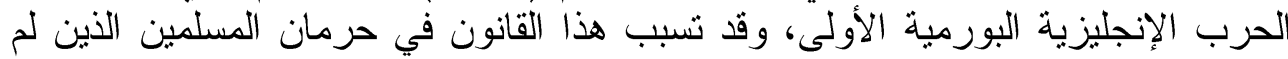
يتمكنو ا من تقـديم هذه الوثائق من حق الموالطنة الكاملة وما بترثب عليه من حقوق

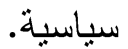
المطلب الثالث: صور الاضطهاد المتنالي بحق الروهينجا:

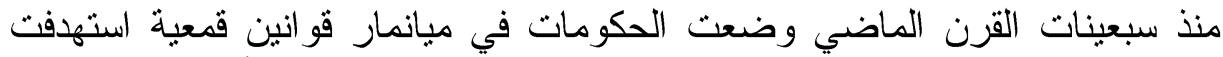

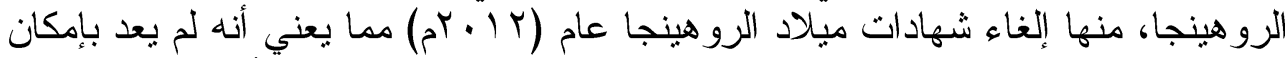

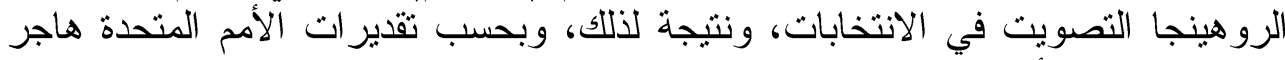

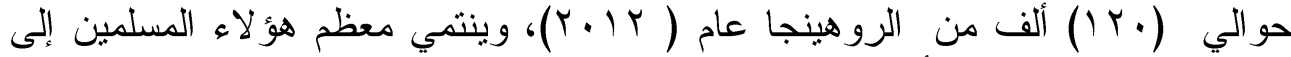

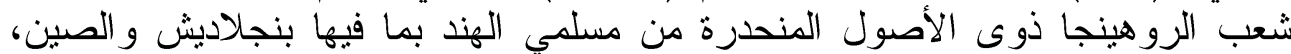

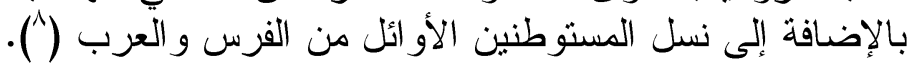

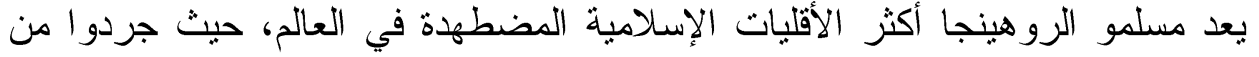

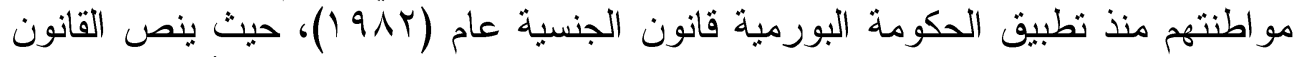

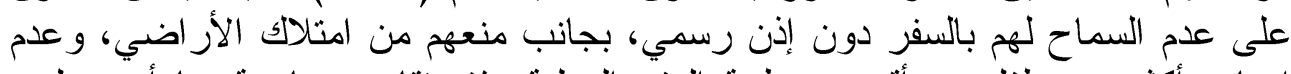

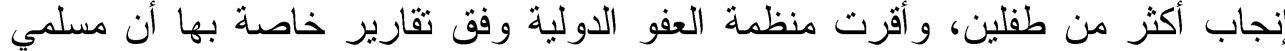
الروهينجا لايزالون يعانون من انتهاكات لحقوق الإنسان في ظل التهات المجلس العسكري

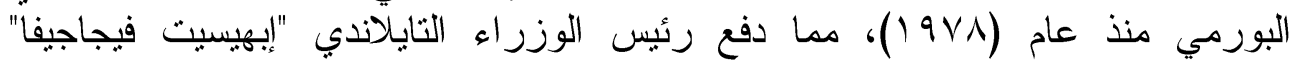

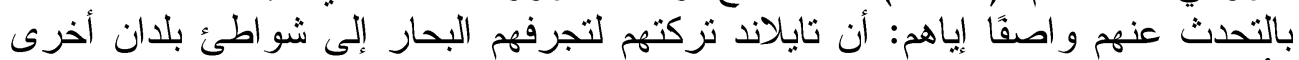

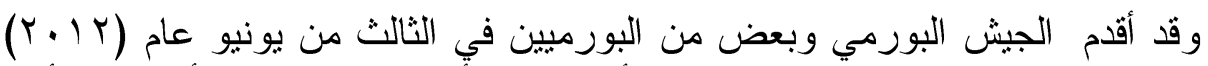

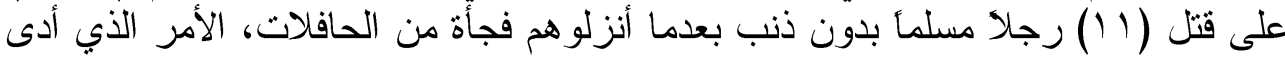

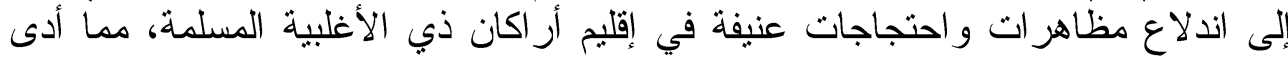

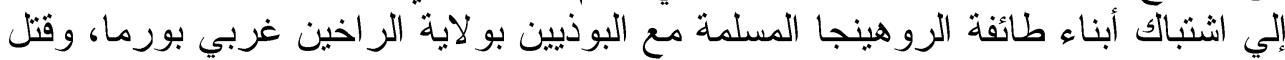

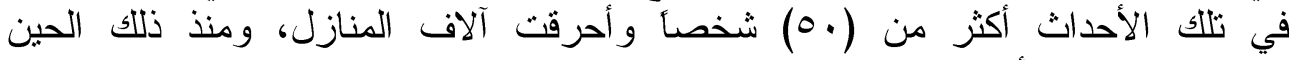
تصاعدت وتيرة الأحداث وما يز ال مسلمو بورما يعانون الطرد و الترحيل و القتل و التعذيب

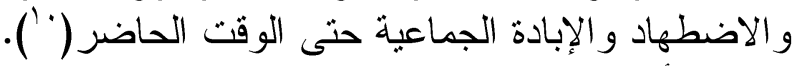

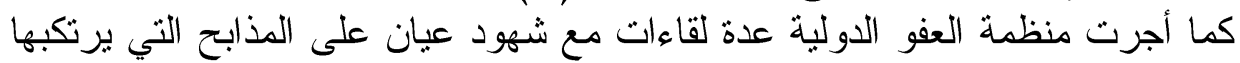

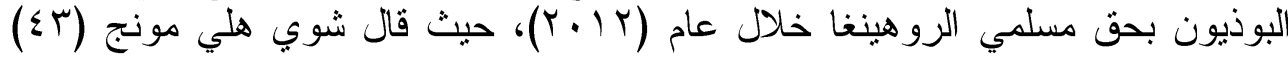

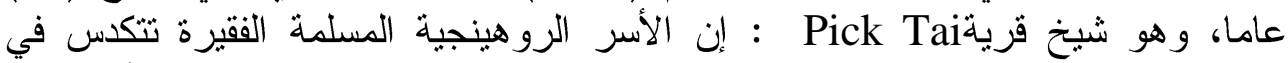

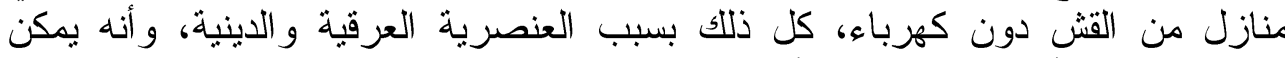
لحكومة بورما أن تحل ذللك إذا أر ادت في غضون خمس دقائق، ولكنها لا تفعل شيئا لصالح الروهينغا. 


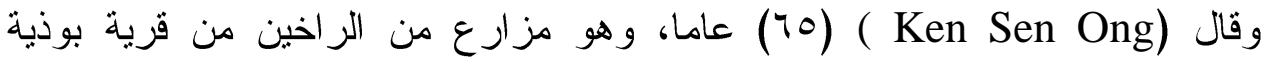

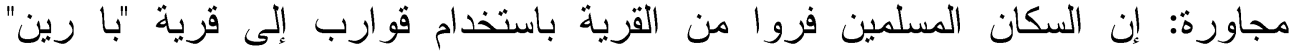

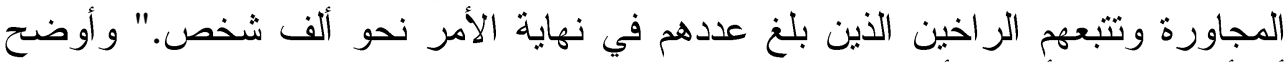

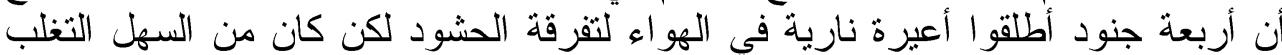

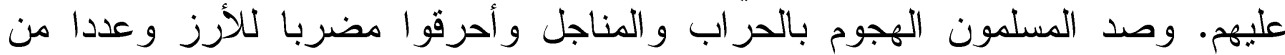

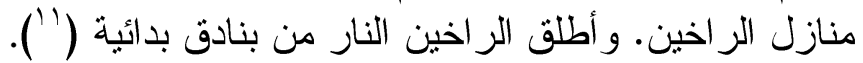

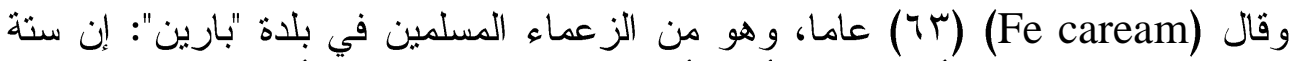

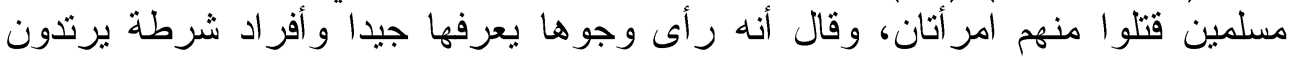

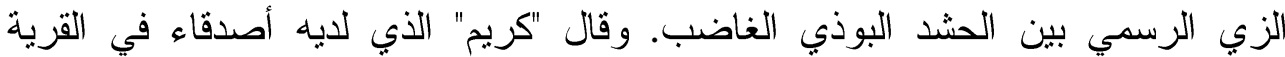

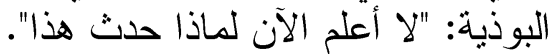

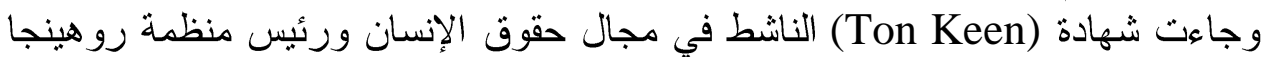

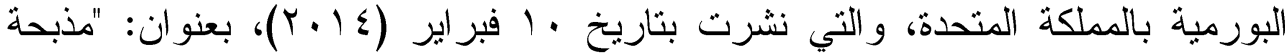

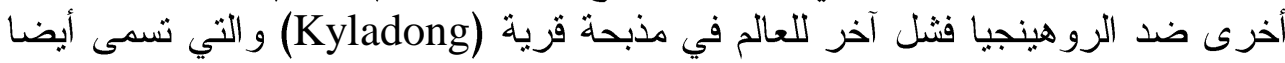

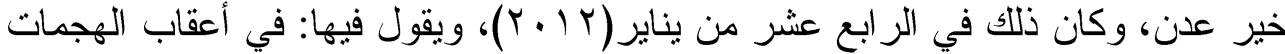

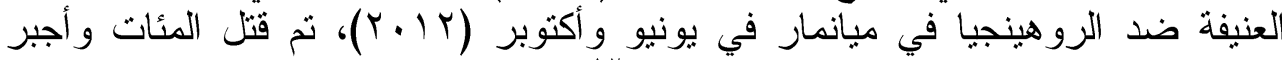

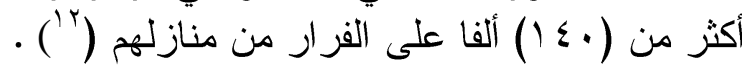

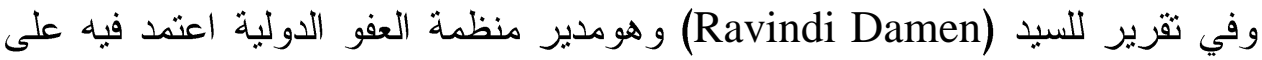

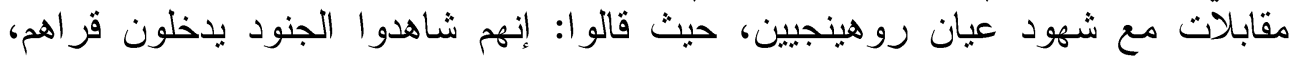

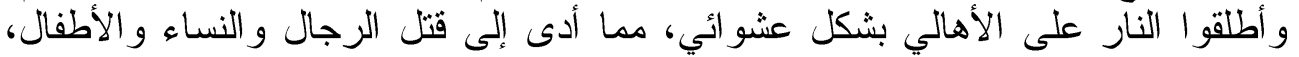

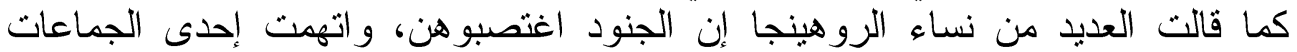

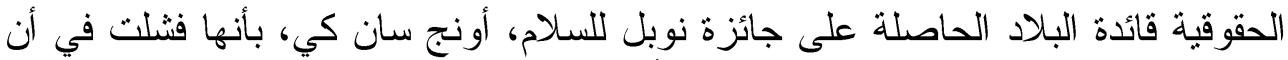

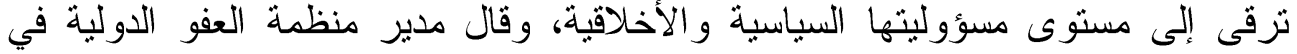

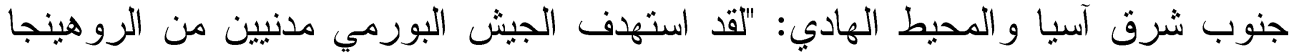

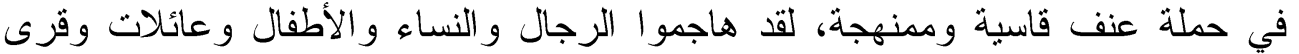

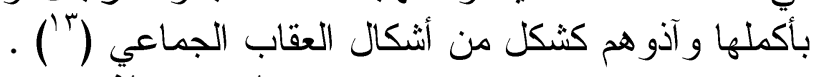
المحة تاريختية الثاني

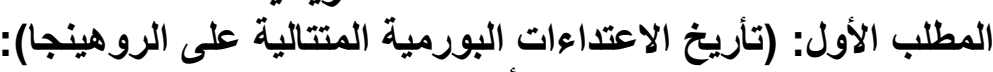

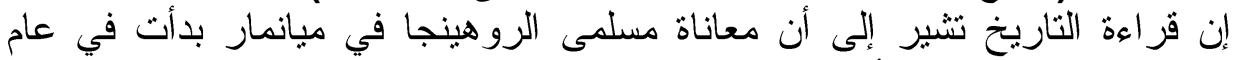

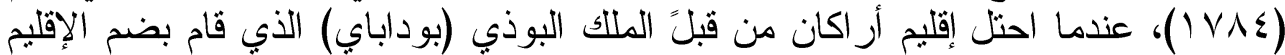

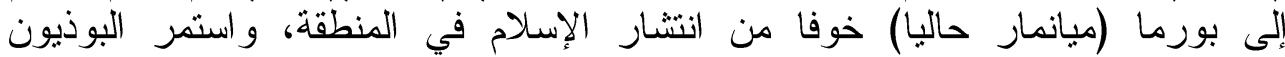

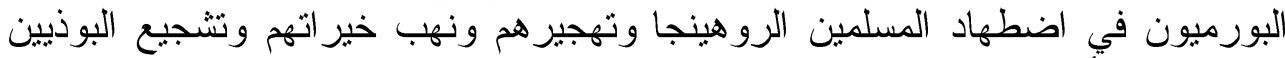

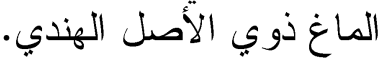

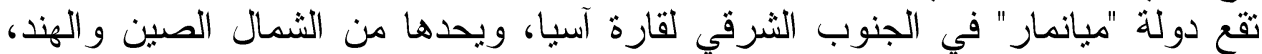

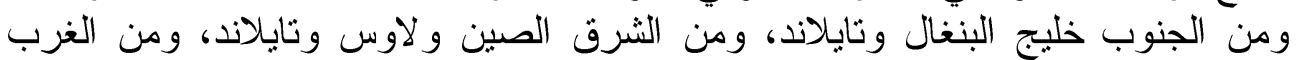

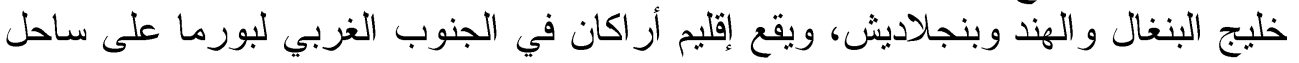

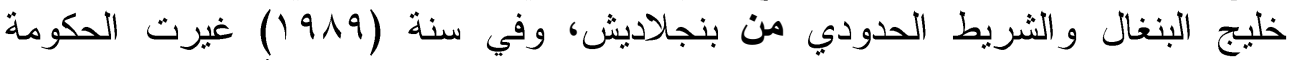

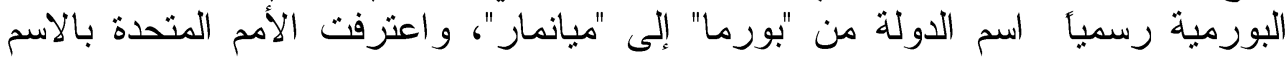

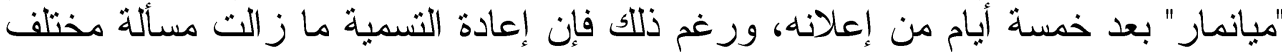


علبها، فالكثير من الدول لا تز ال تعتزف باسم الدولة كـ"بورما" منها استر البا، وكندا،

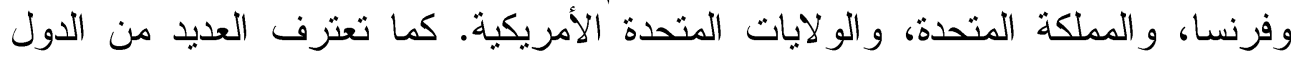

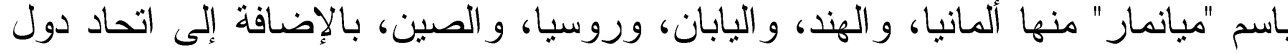

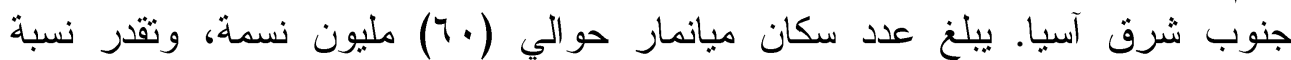

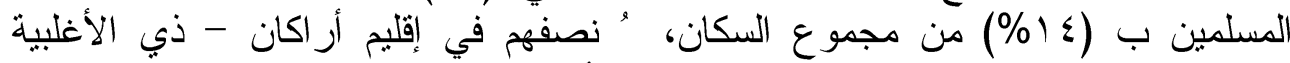

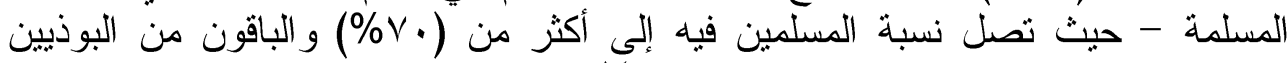

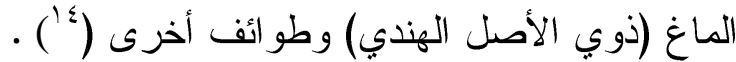

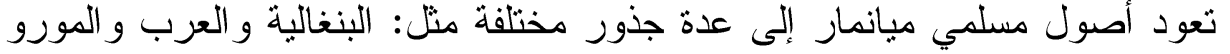

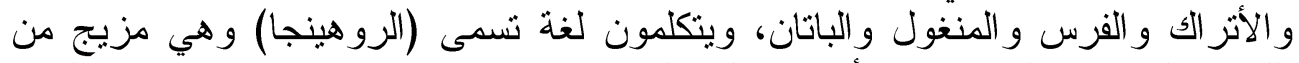

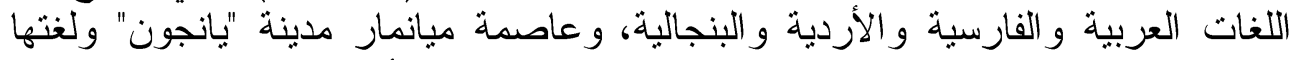

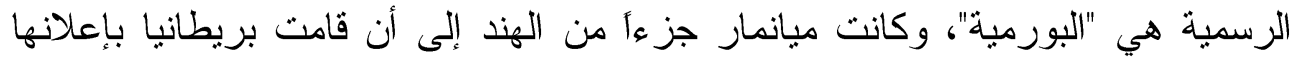

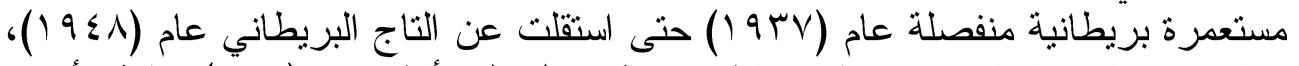

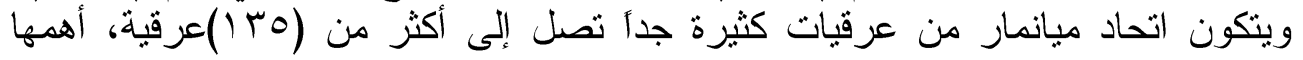

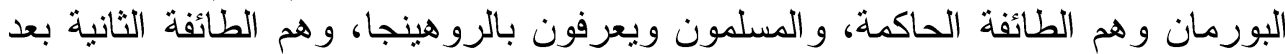

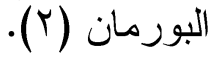

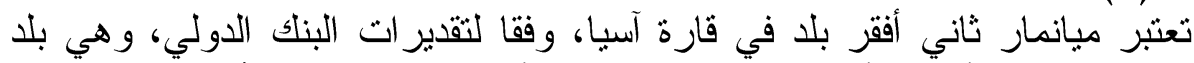

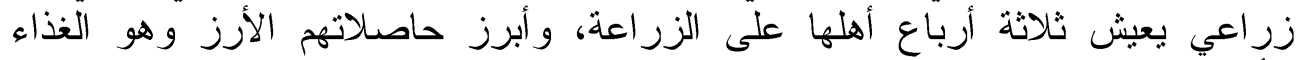

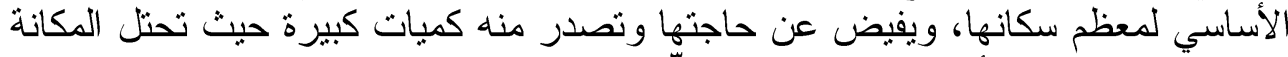

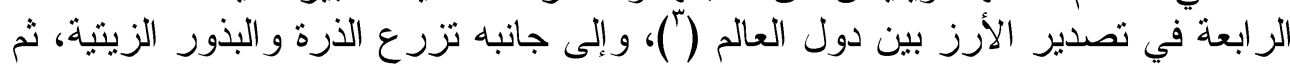

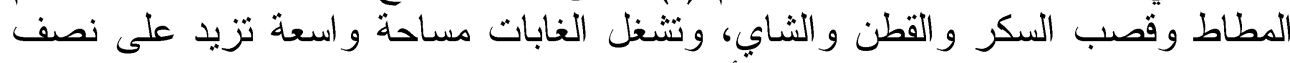

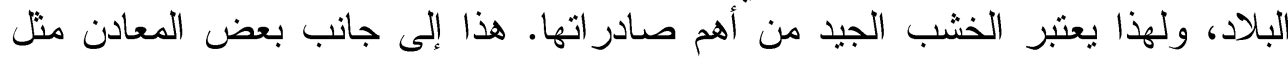
القصدير و الرصاص ولهذ و الأنتيمون و البترول.

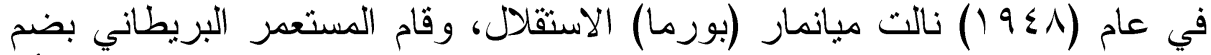

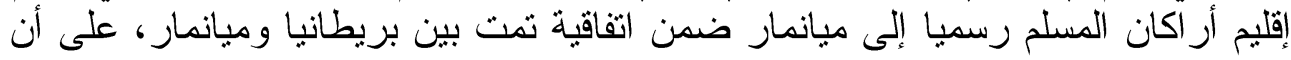

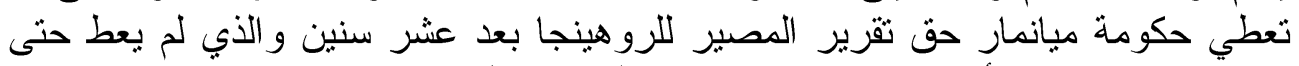

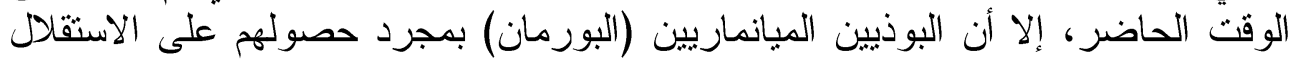

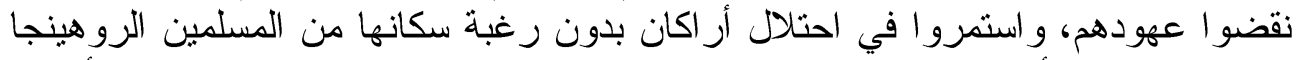

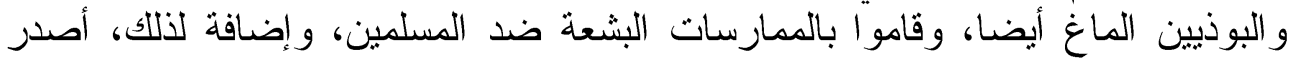

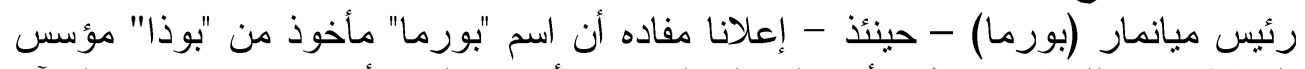

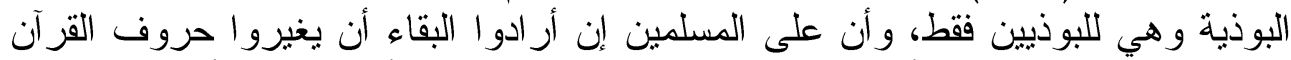

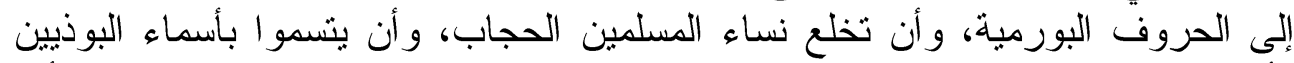

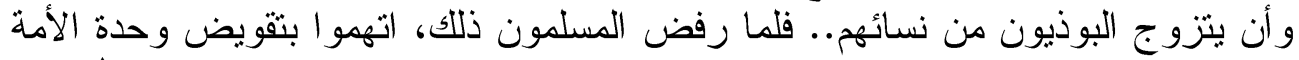

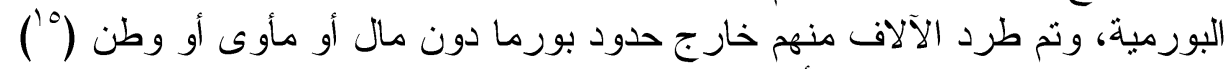

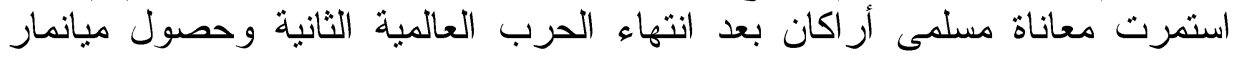

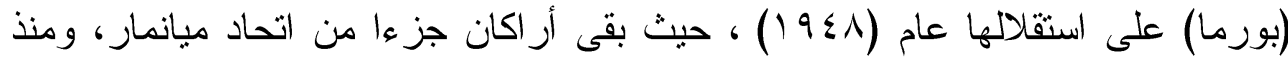

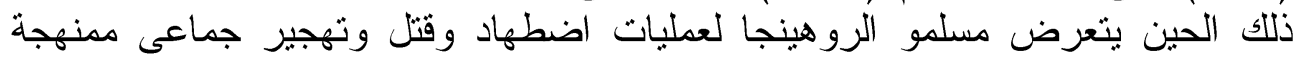

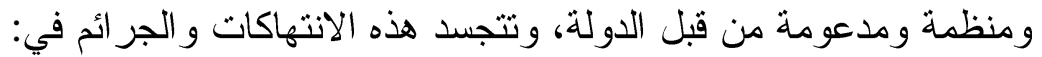

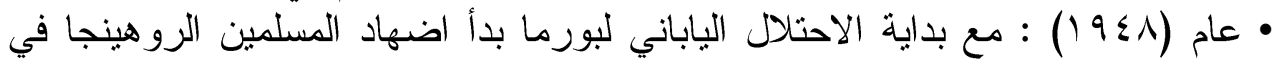




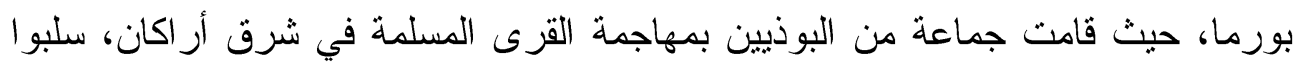

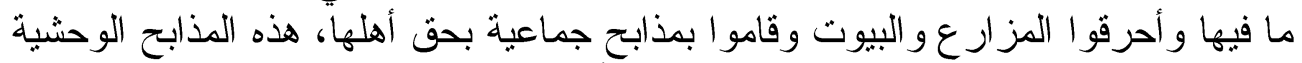

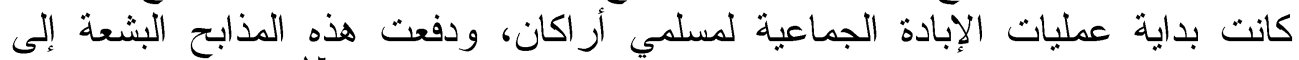

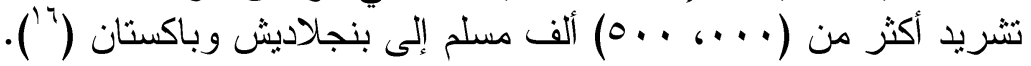

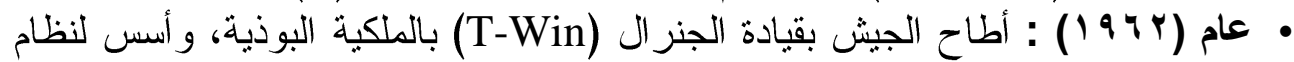

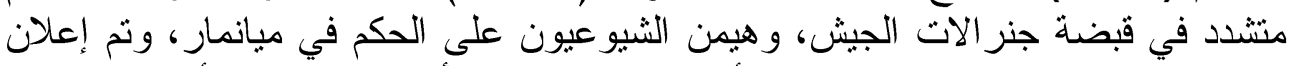

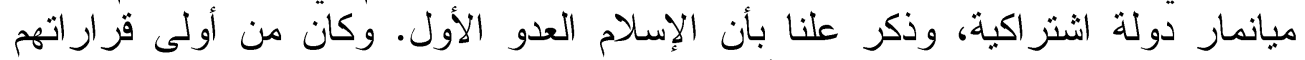

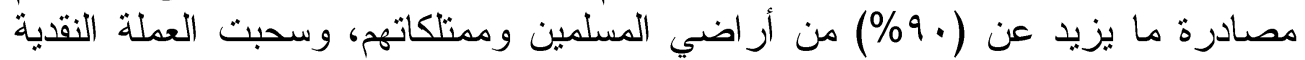

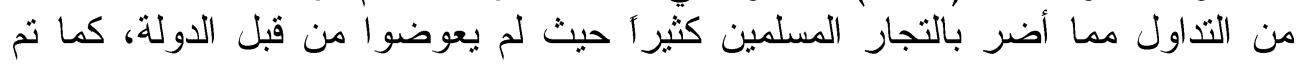

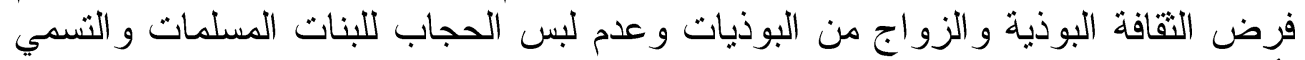

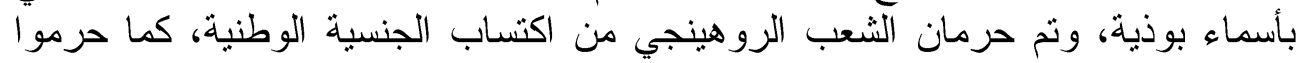

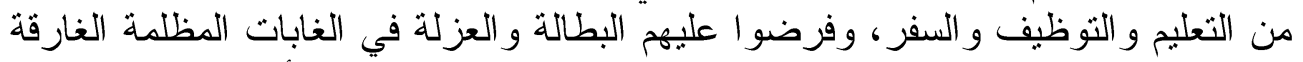

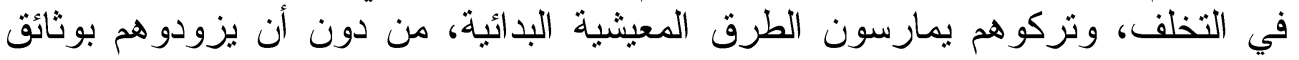

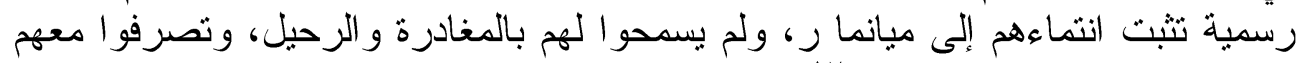

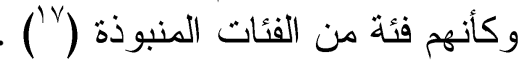

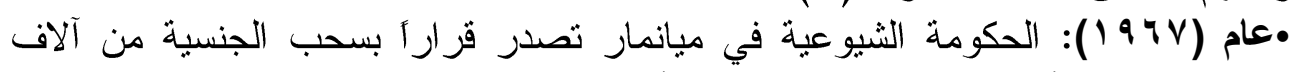

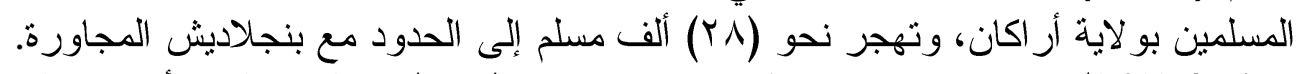

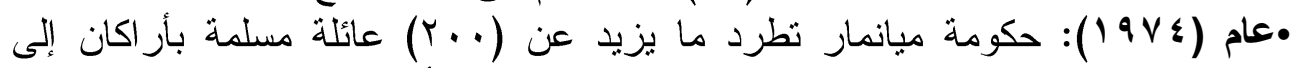

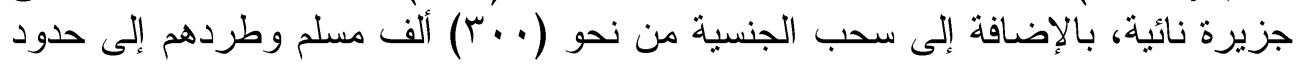
بنجلاديش.

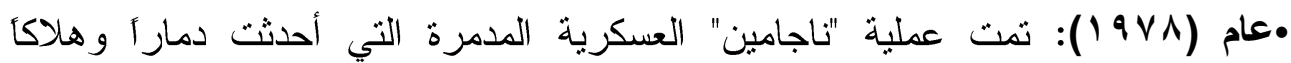

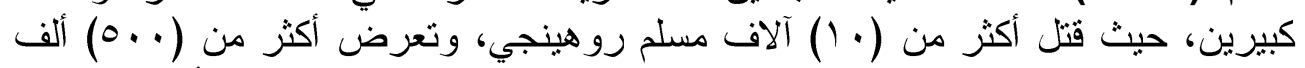

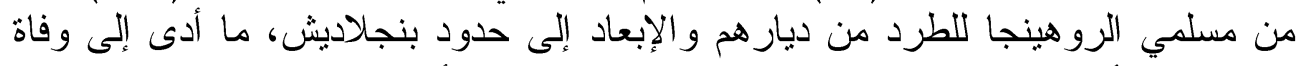

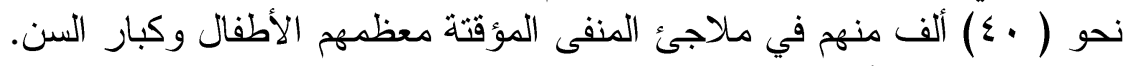

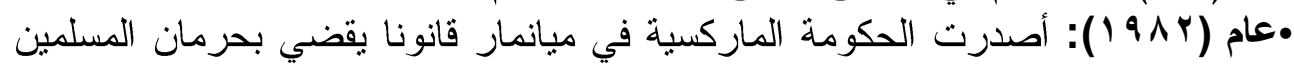

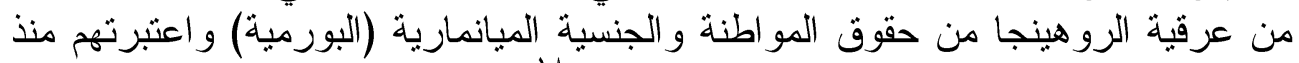

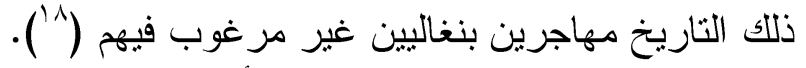

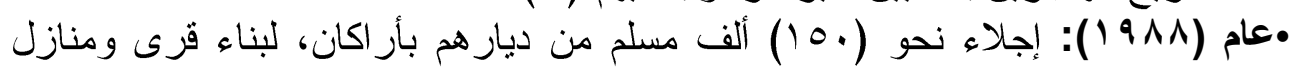
للبوذيين في إطار محاو لات تغيير التركيبة الديمجر افية للواء لاية.

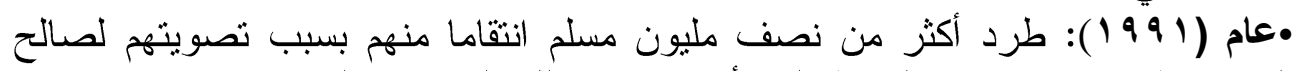

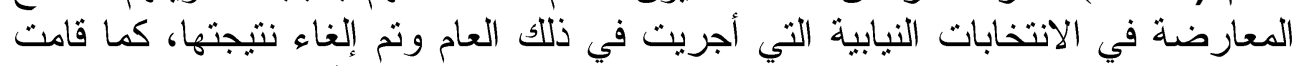

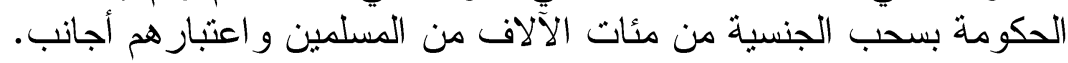

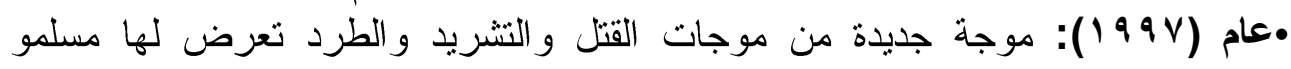

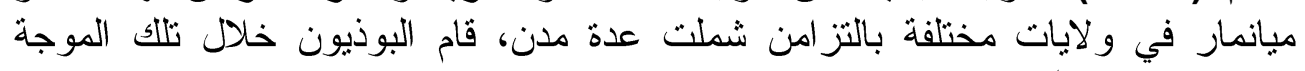
بحرق عشر ات المساجد.

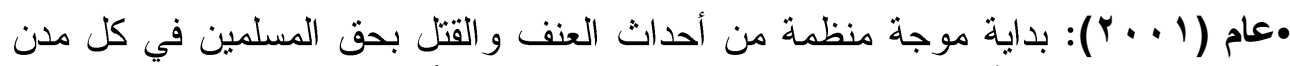

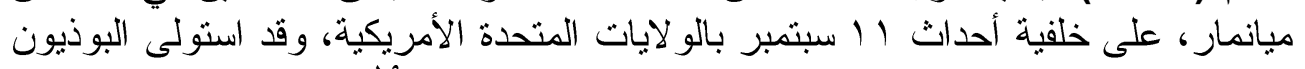

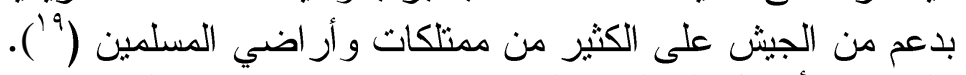

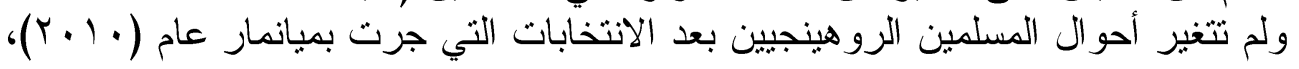


حيث استمر مخطط الانتهاكات والتطهير العرقي والتهجير للمسلمين من أر اكان موجودأ،

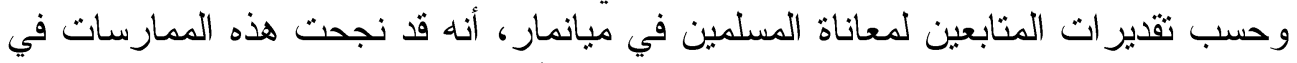
تهجير حو الي من (r-צ) ملايين مسلم حتى الآن، و أسفرت عن مئات الآلاف من القتلى.

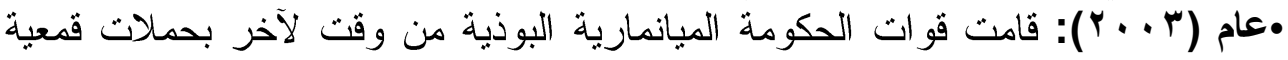

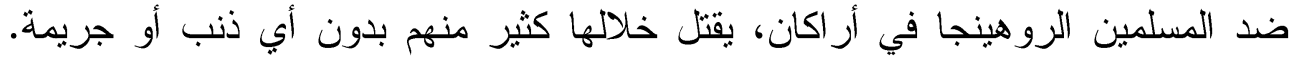

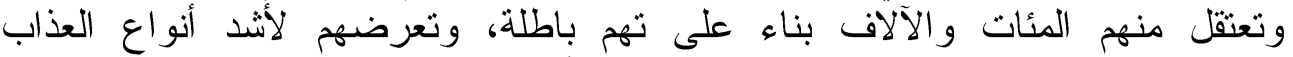

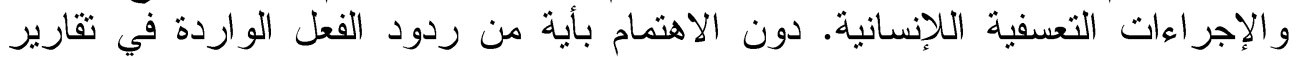

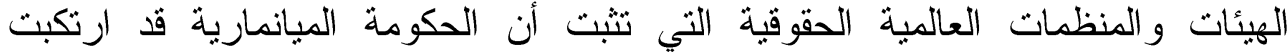

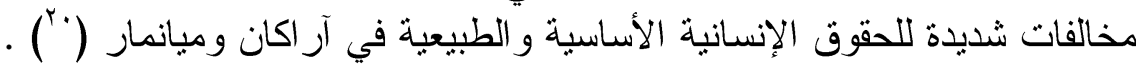

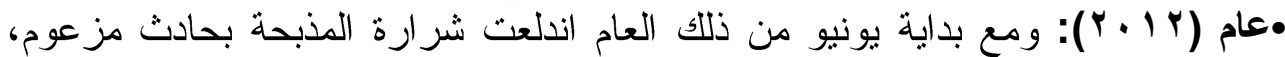

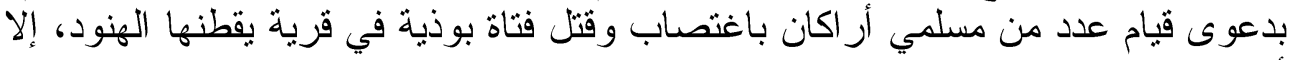

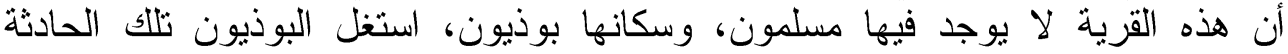

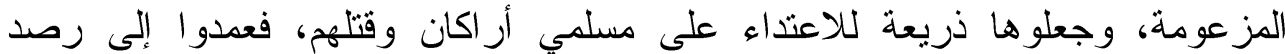

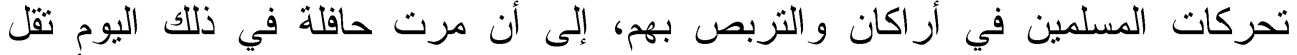

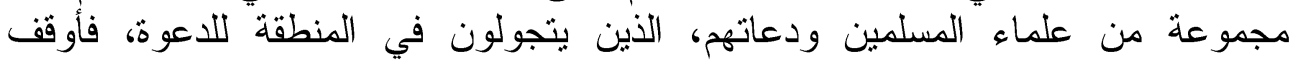
مجموعة من البوذيين المتطرفين هذه الحافلة، وقتلو ا عددأ كبير أ من ركابها، وعلى العلى إثرها

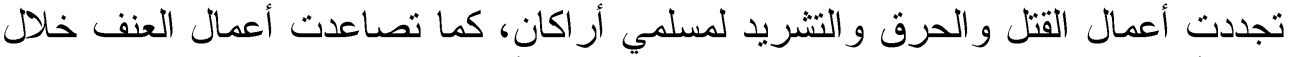

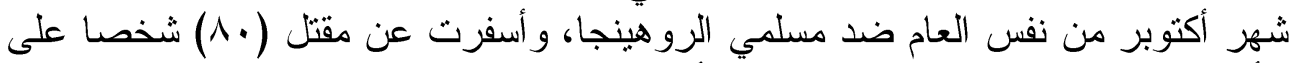

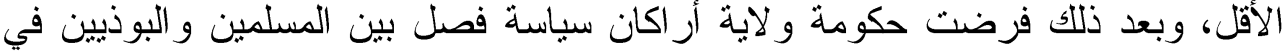

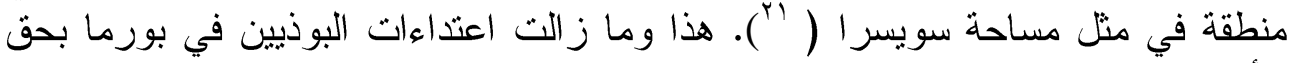

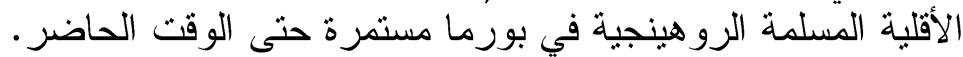

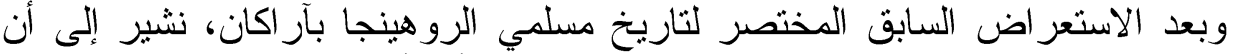

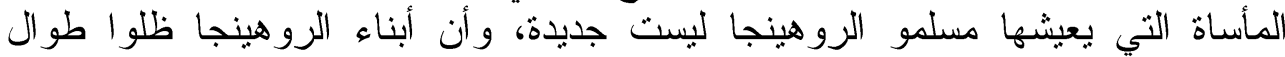

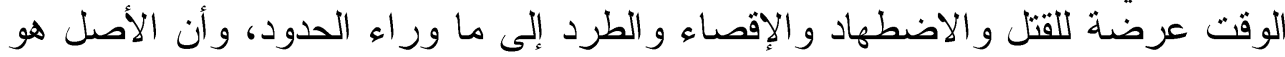

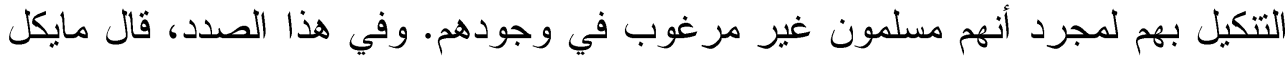

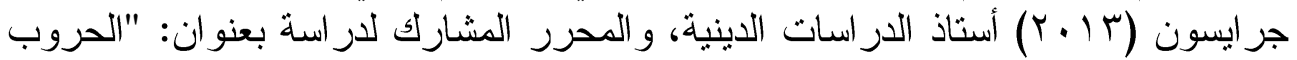

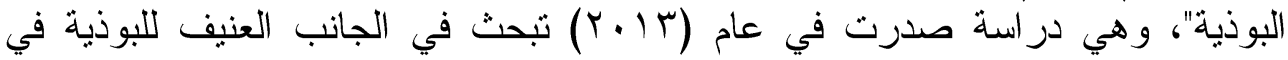
جنوب شرق آسيا، وكيف استخدمت المنظمات البوذية هناك الصور الكية الدينية و الخطب

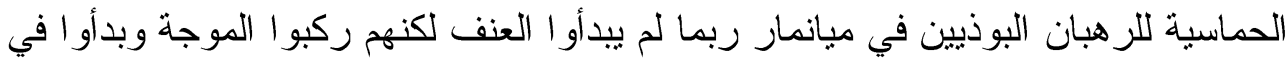

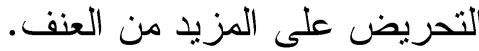
المطلب الثاني: مقاومة الاضطي المهاد:

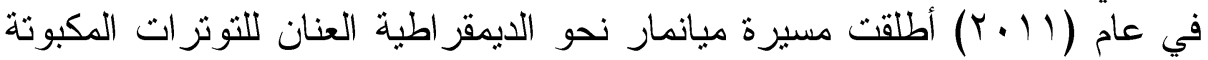

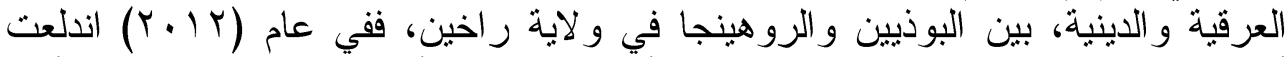

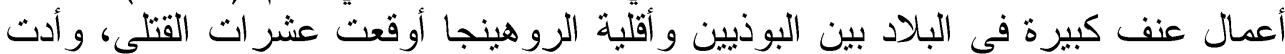

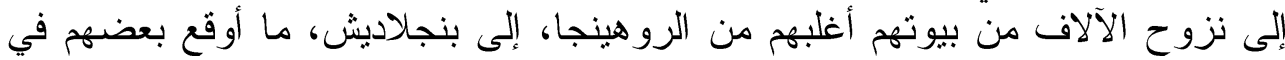
قبضة متاجرين بالبشر، كما قام الجيش البورمي بعملية عسكرية إثز مهاجمة مسلحين 


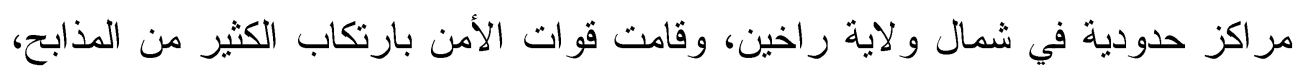

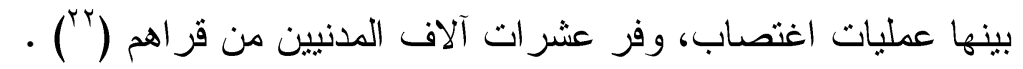

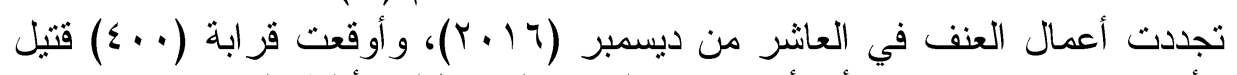

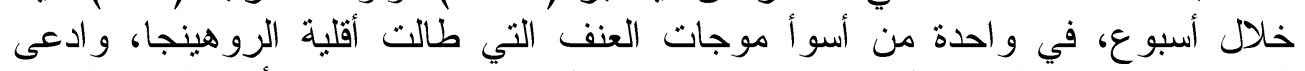

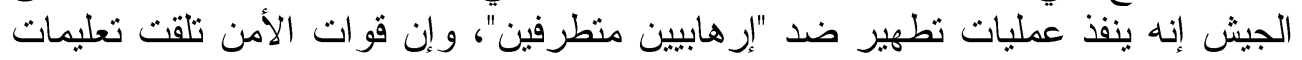

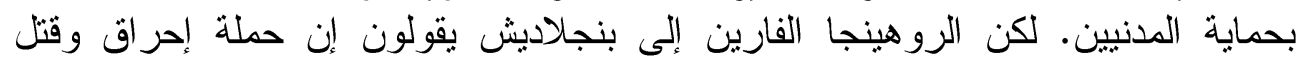

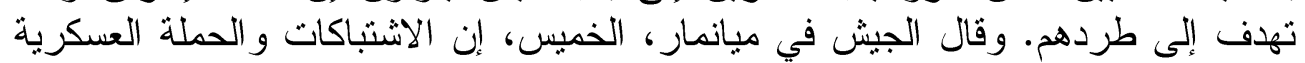

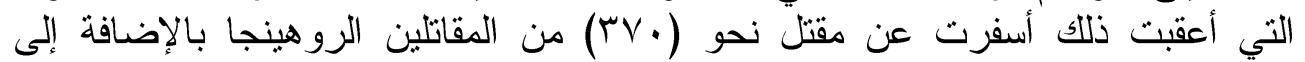

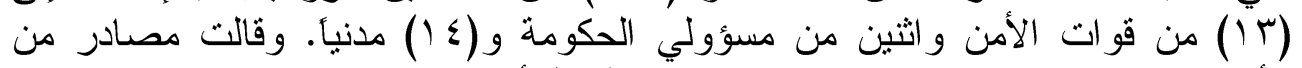

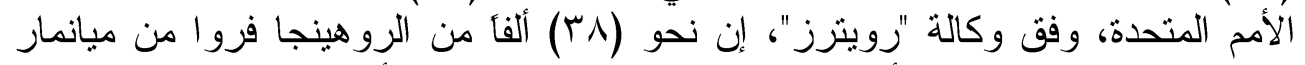

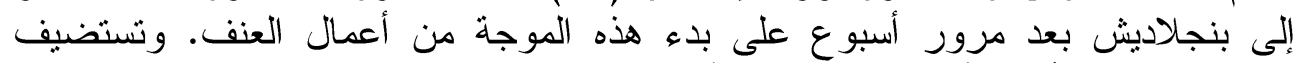

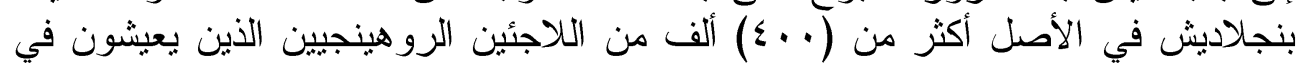
مخيمات بائسة قريبة من الحدود مع مبانمار ، وطلبث تكر ارأ من ميانمار استعادة اللاجئين

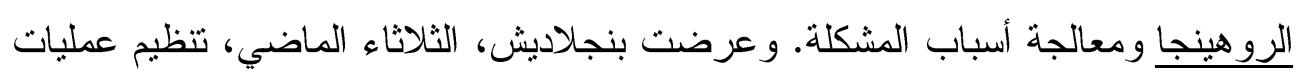

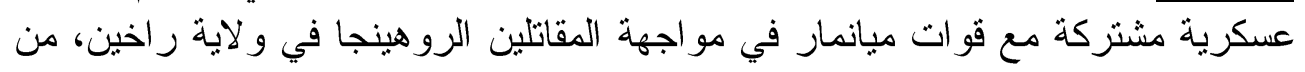

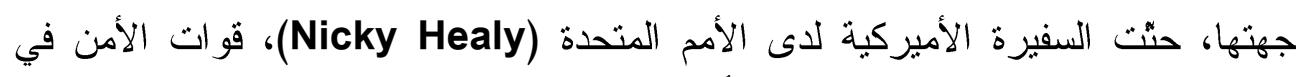

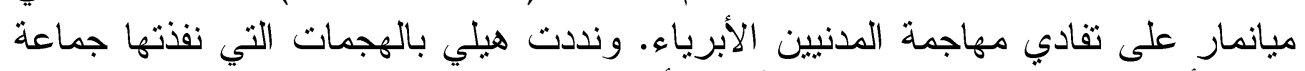

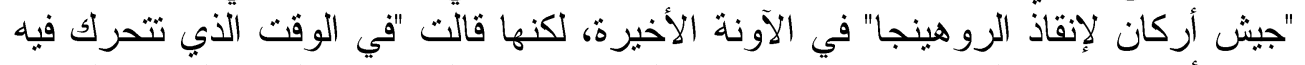

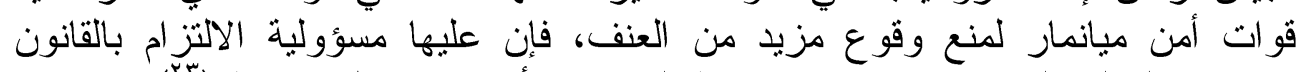

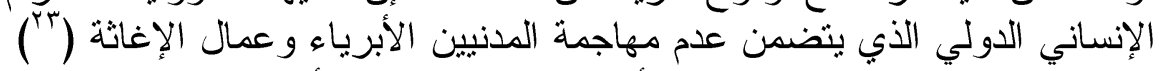

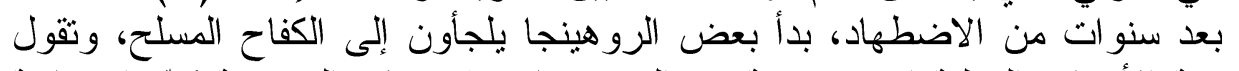

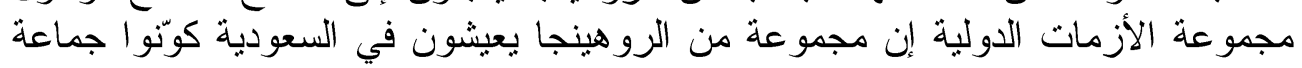

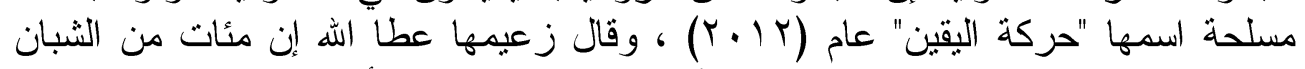

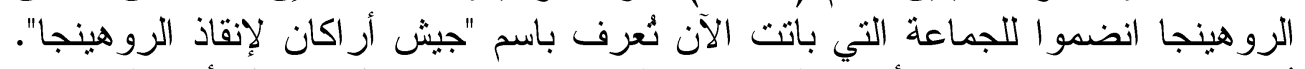

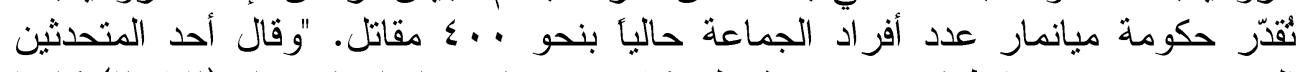

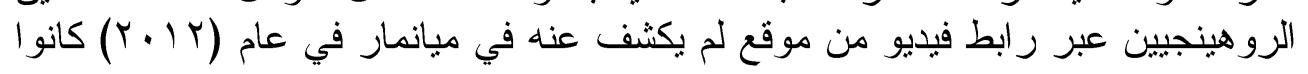

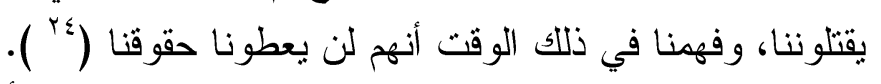

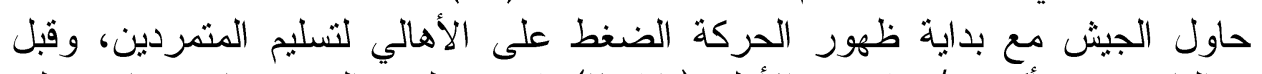

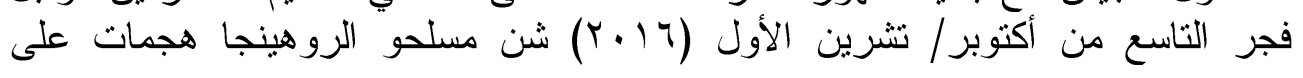

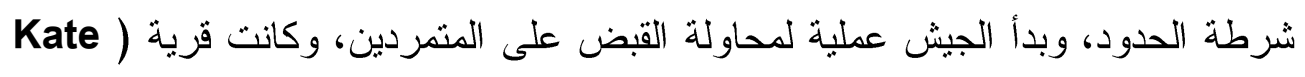
Yue Bien

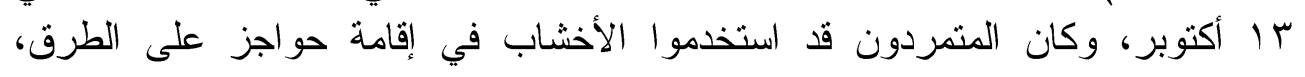

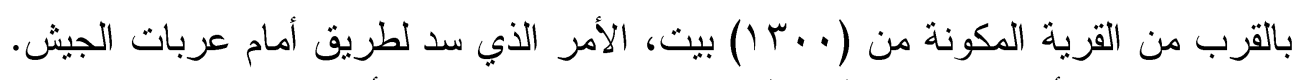

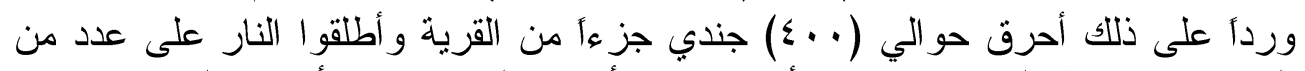

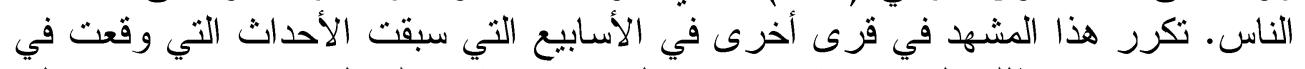

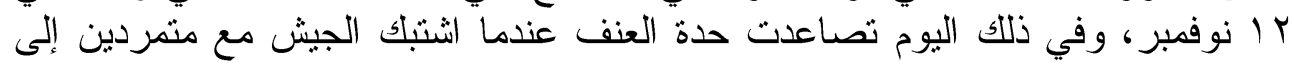




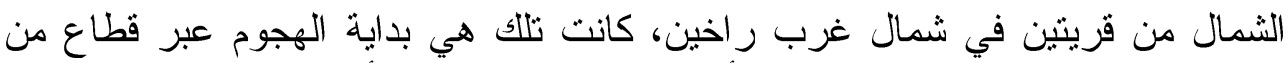

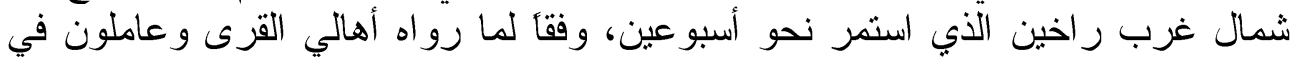
مجال المساعدات الإنسانية ومر اقبو حقوق الإنسان، وفرّت مجموعات غفيرة شماه الا باتجاه

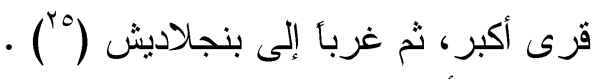

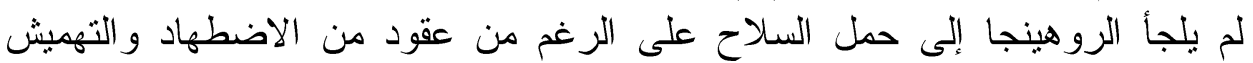

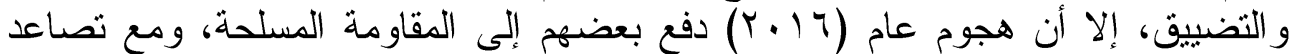

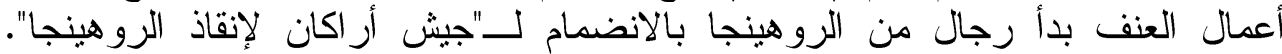

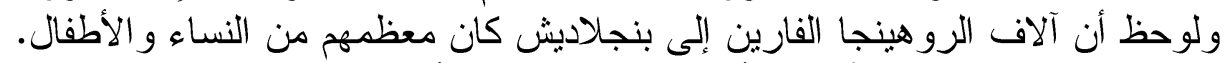

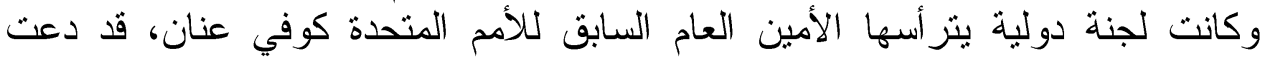

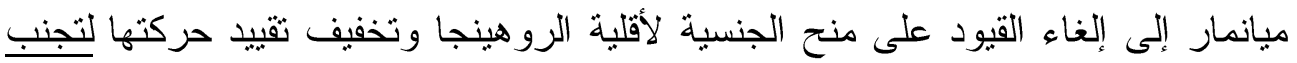
Aung San Suu ) تطرفها واحلال السلام في و لاية راخين. وكانت رئبسة الحكومة (Kyi

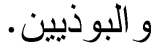

ونشرت اللجنة تقريرها محذرة من أن عدم تطبيق توصياتها بمكن أن يؤدي إلى مزيد

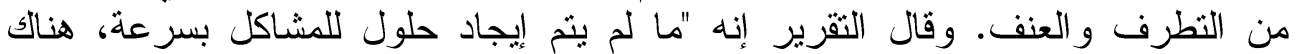

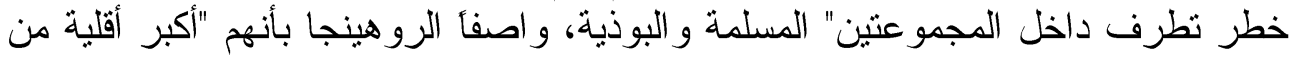

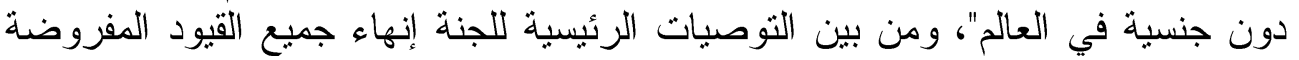

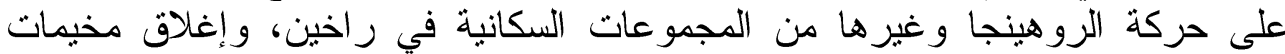

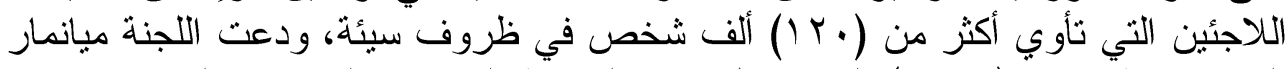

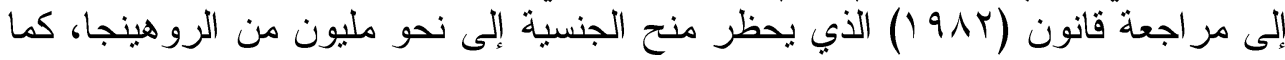

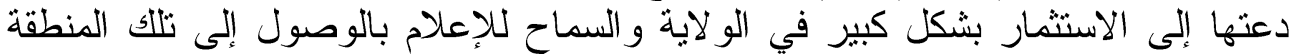

\section{المبحث الثالث}

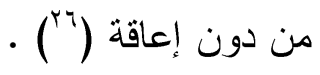

\section{المواقف الدولية والعربية والإسلامية تجاه هذه اضطهاد الروهينجا في ميانمار}

شهد العالم وما زال موجة من أعمال الاستكار والإدانة لما يحصل من إبادة

$$
\text { تمهيخ: }
$$

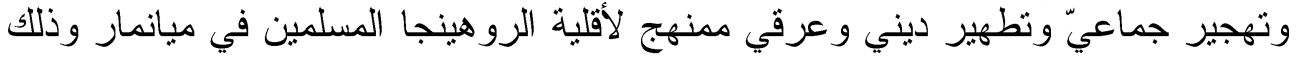

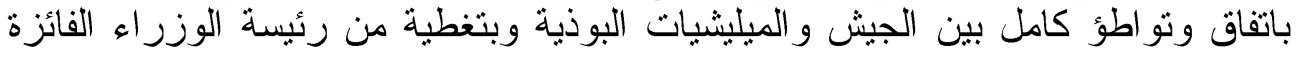

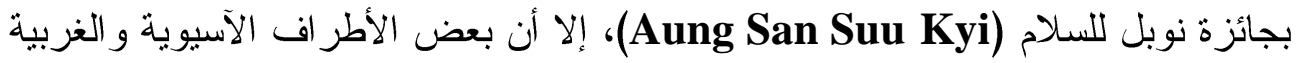

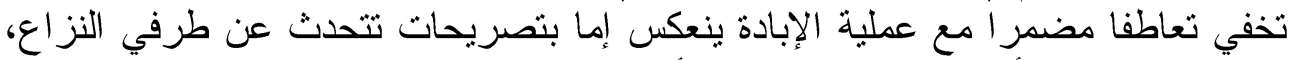

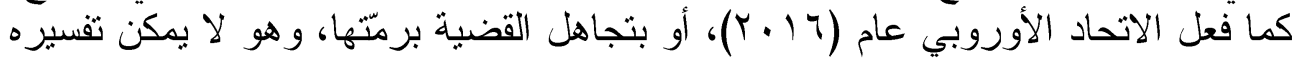

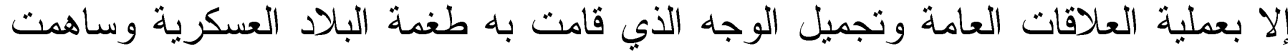

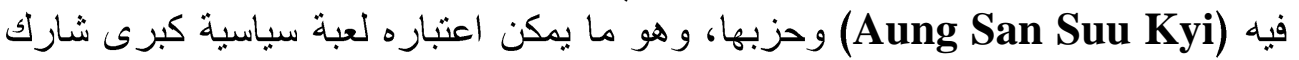

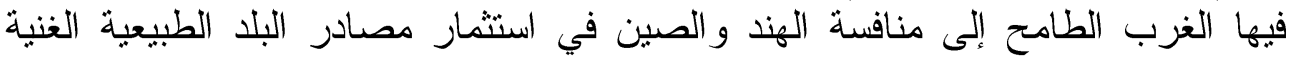

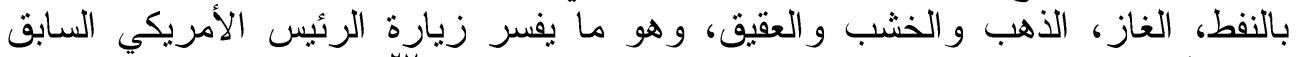

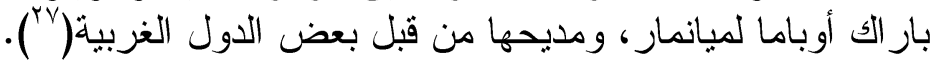


كما إن تكرار الاعتداءات ضد المسلمين الروهينجا غالبا ما كانت مصحوبة بتغافل

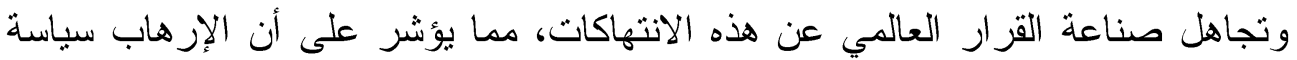

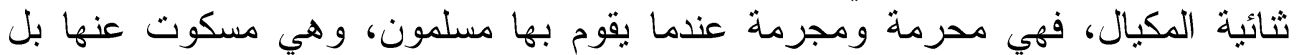

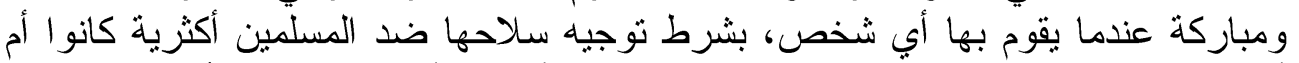

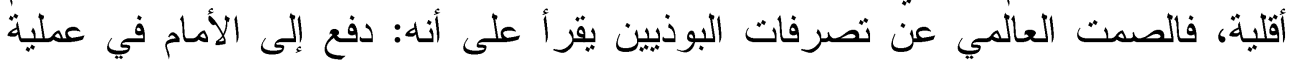

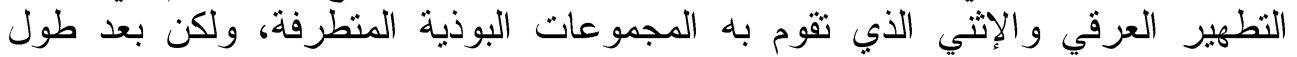

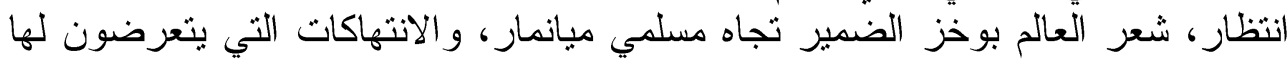

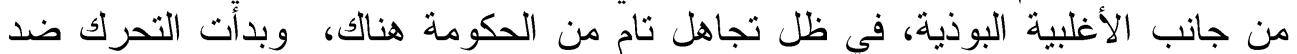

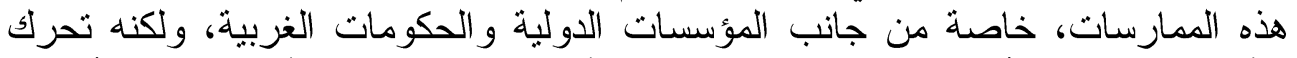

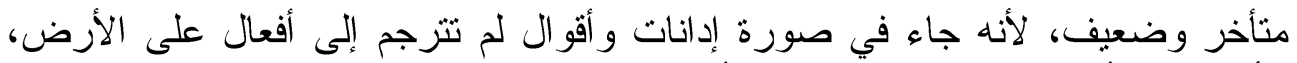

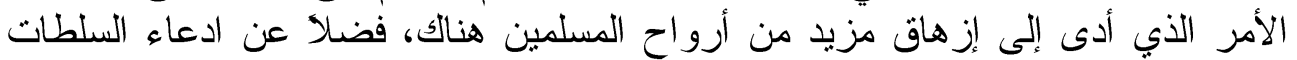

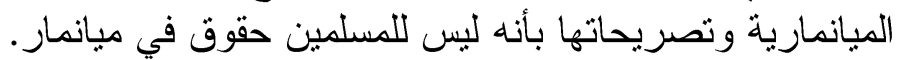

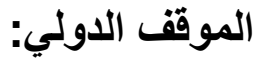

اتفقت آراء دول العالم حول ملف ميانمار أمام الدورة الثانية و العشرين العادية

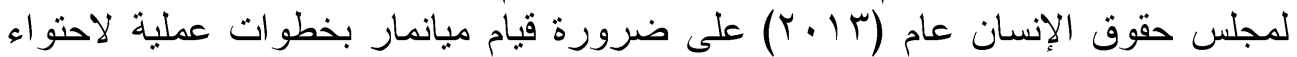

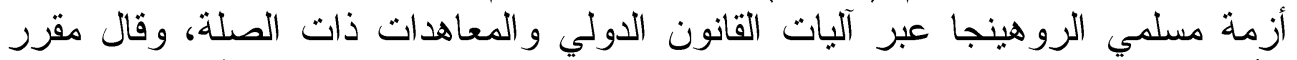

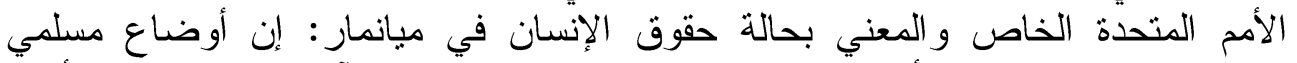

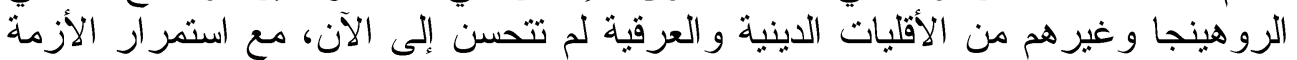

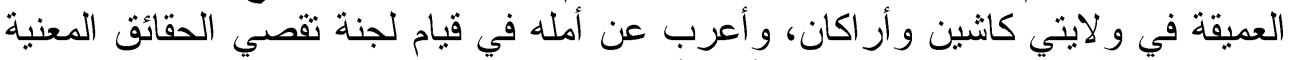

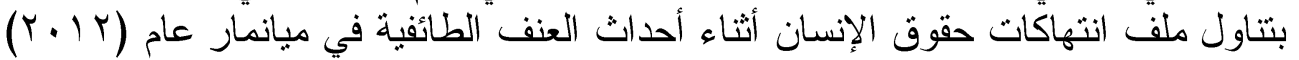

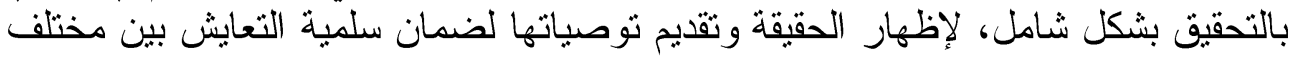

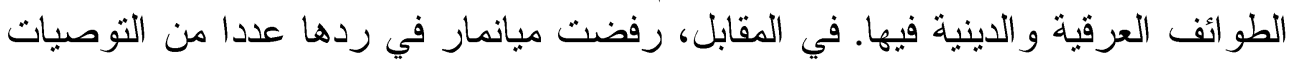
و الملاحظات الواردة في تقرير مجلس حقوق الإنسان دون أن تسميها، مؤكدة أنها "تثعاون

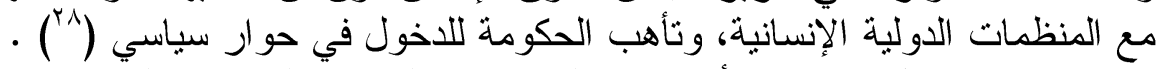

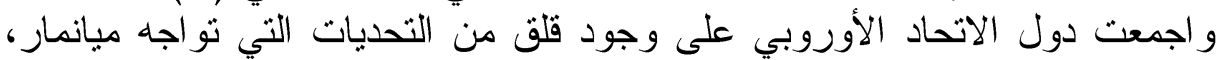
لاسيما تلك المتعلقة بحقوق الأقليات الدينية والعرقية مثل تحسين أوضاعها الإنسانية

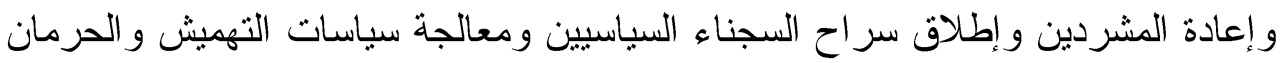

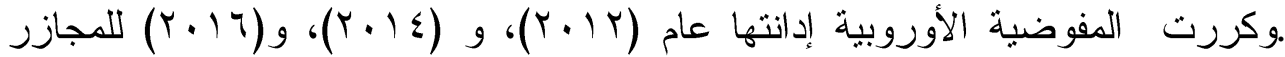
التي ترتكبها جماعات بوذية منطرفة ضد المسلمين في ميانمار ، و التي أودت بحت بحياة ألآف المسلمين.

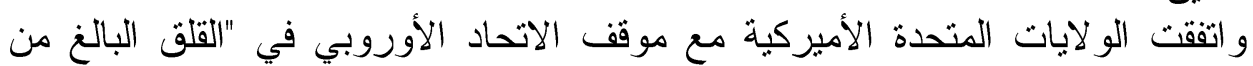

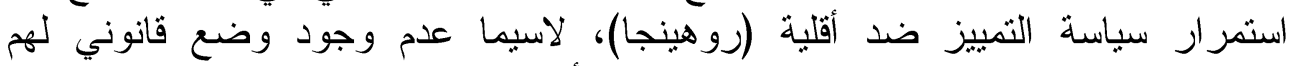

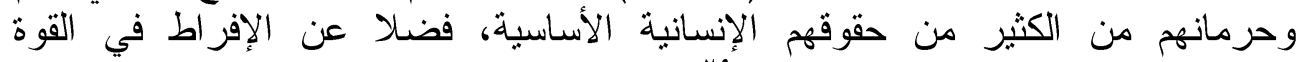

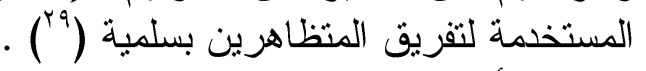

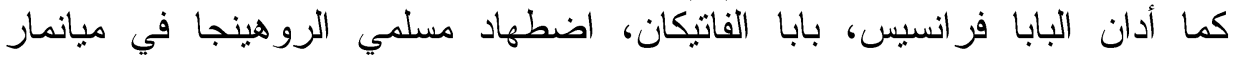

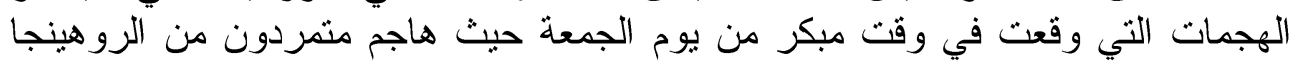

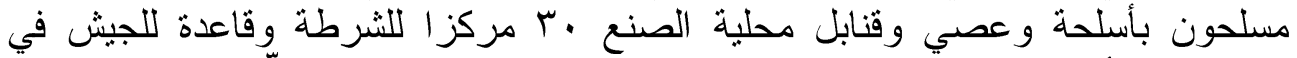

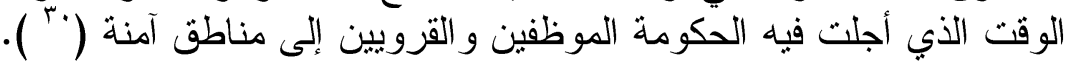




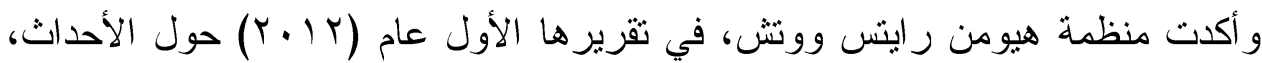

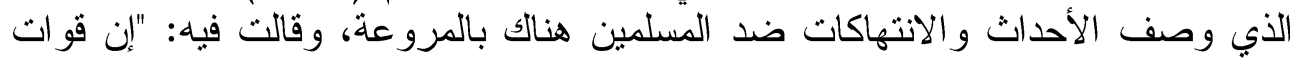

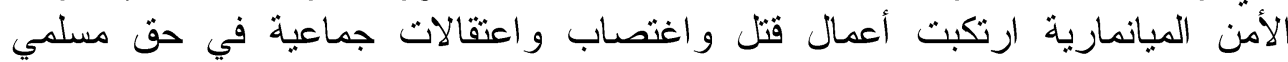

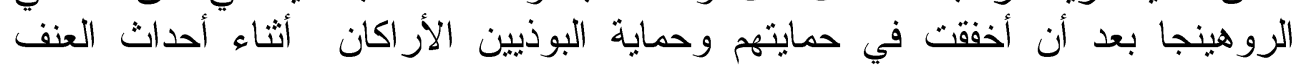

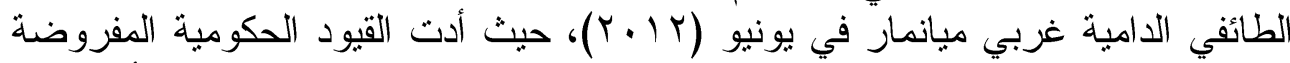

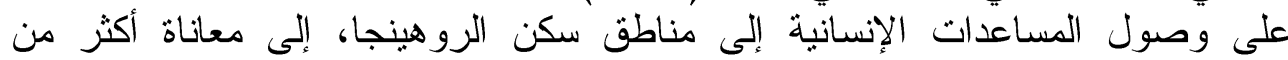

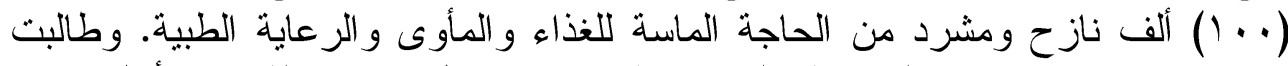

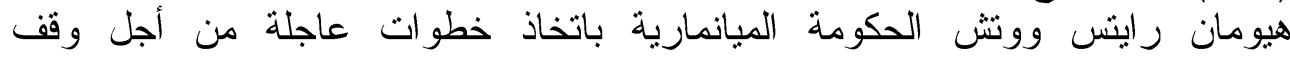

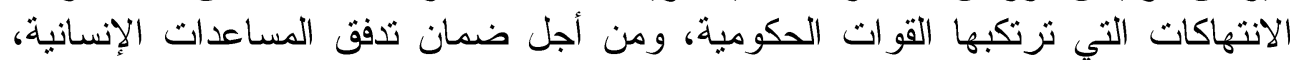
وأن تسمح للمز اقبين الدوليين المستقلين بزيارة المناطق المتأثرة بالأحداث للتحقيق في الأني

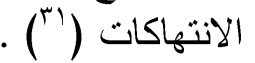

\section{موقف دول جنوب شرق آسبا:}

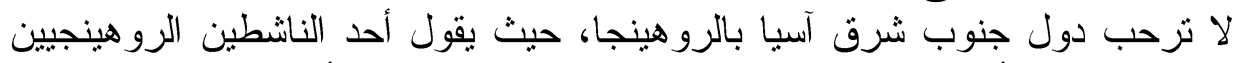

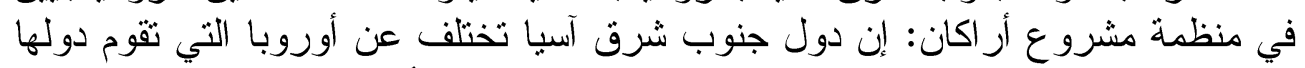

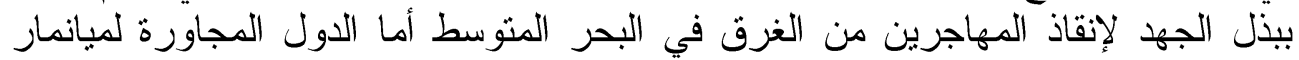

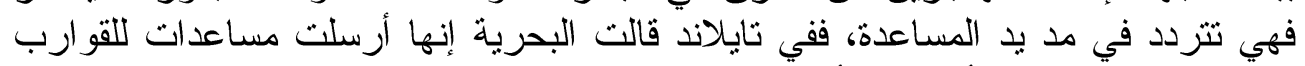
في مياهها الإقليمية وأشارت بأنها قد تسمح بنزول فايلان المهاجرين في مخيمات ولكن دون إقامة دائمة.

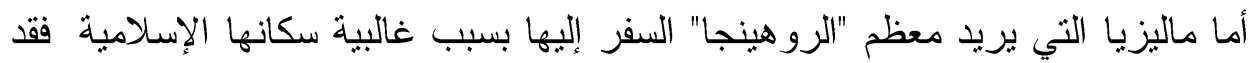

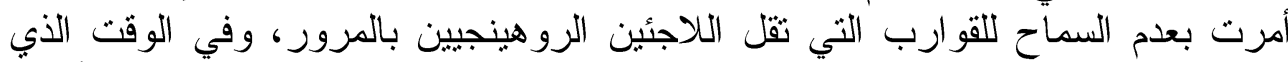

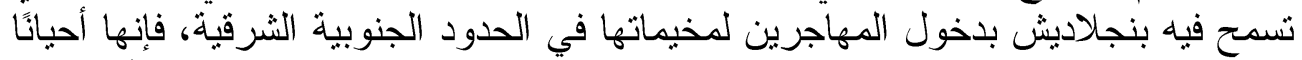

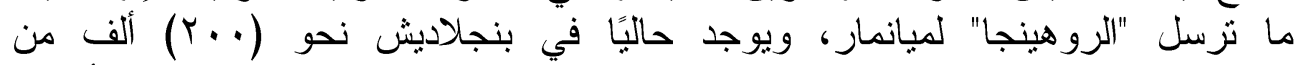

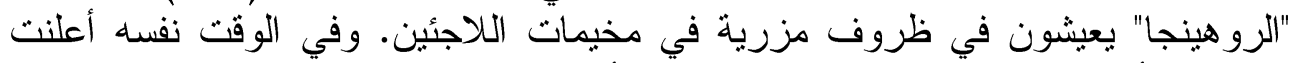

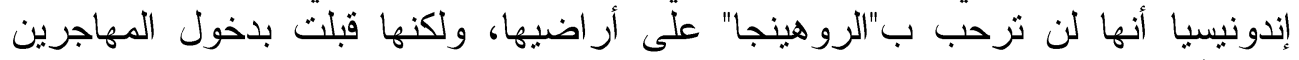

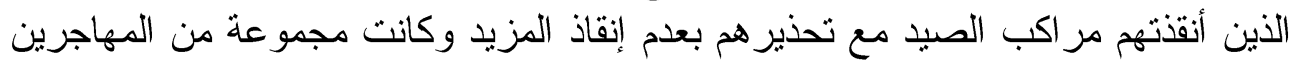

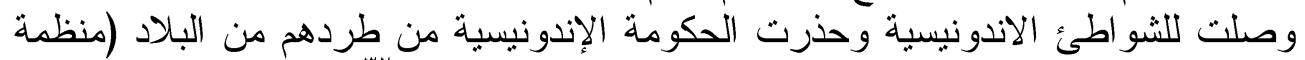

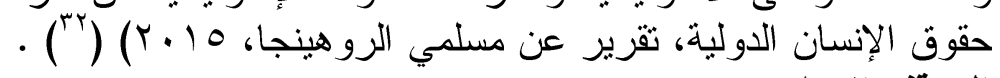

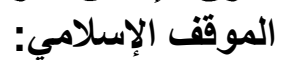
و أما عن مواقفة الإسلاهول الإسلامية فقد حذرت حكومة اندونيسيا نظيرتها في مبانمار

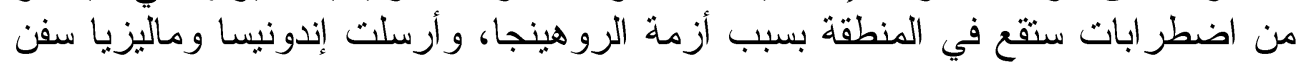

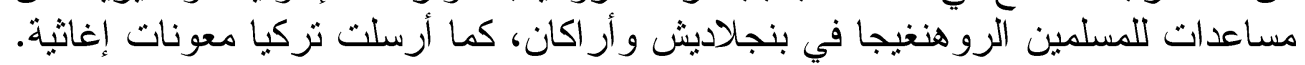

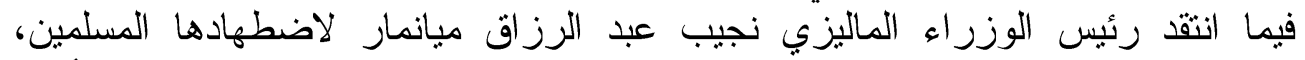

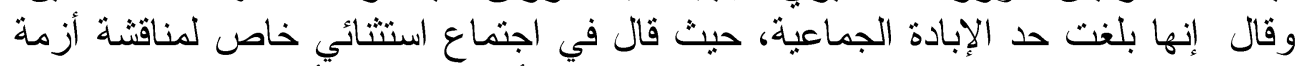

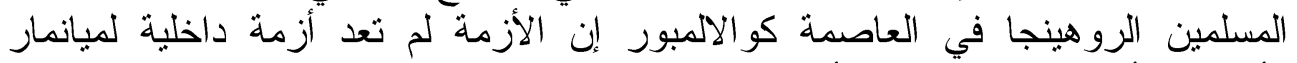
و أصبحت أزمة إقليمية ونوشك فئك أن تكون دولية.

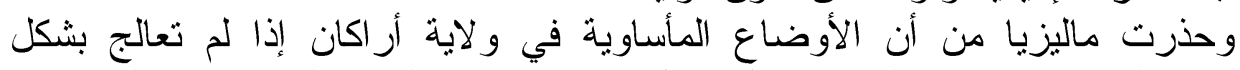

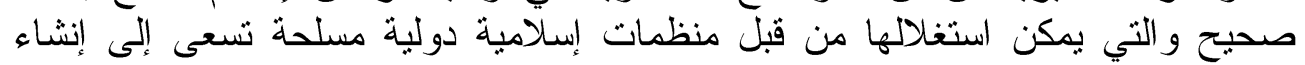
قاعدة لها في جنوب شرف آسيا، مؤكدًا أن قضية الروهينجا ستختبر مدى تضامن دول 
آسبا، حيث إنها بحاجة إلى حلول جذرية لا سيما أنها قضية تمس عو اطف العديد من

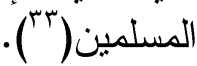

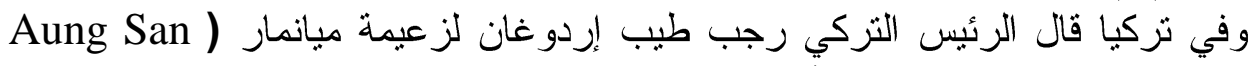
Suu Kyi

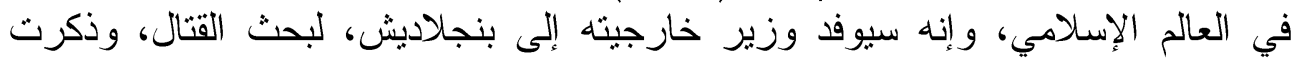

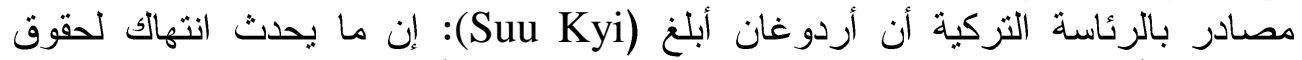

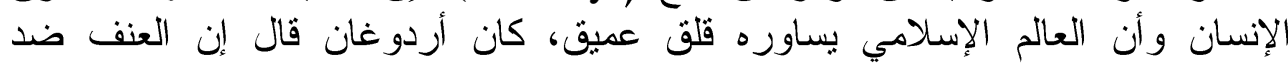

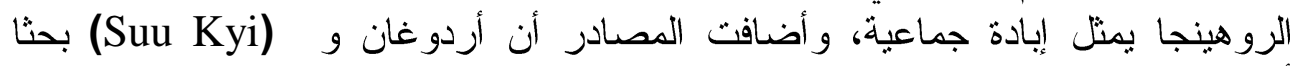

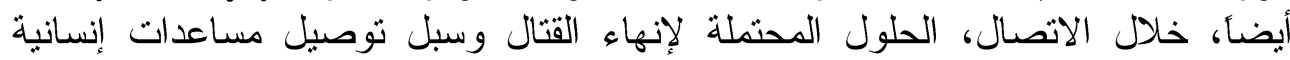

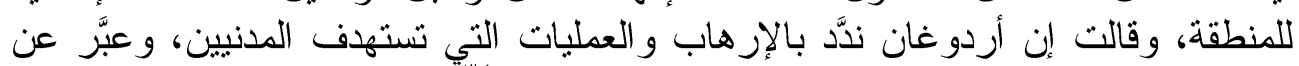

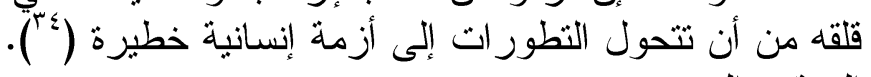
الموقف العربي: ان فئون

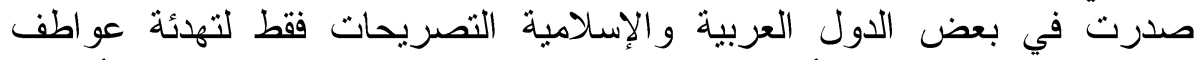

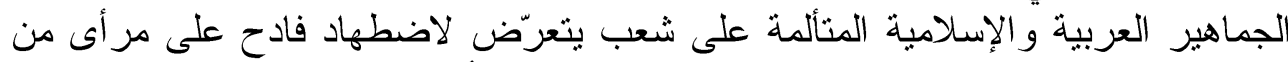

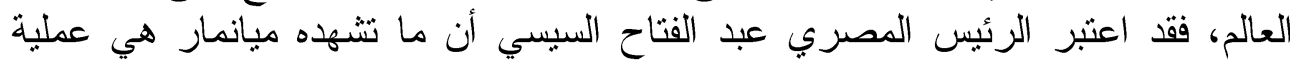

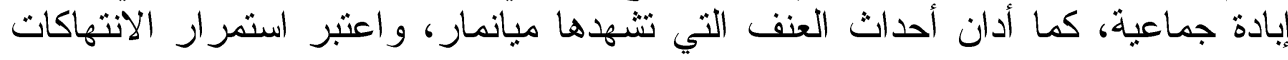

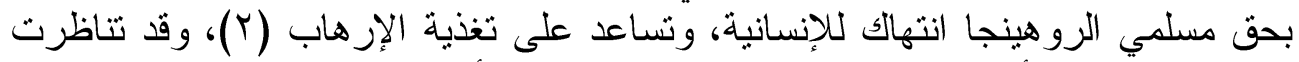

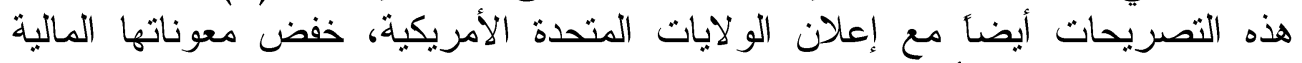

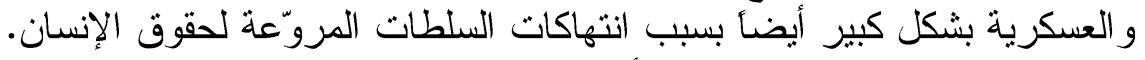

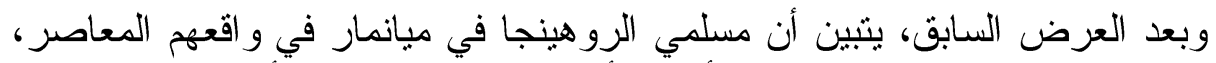

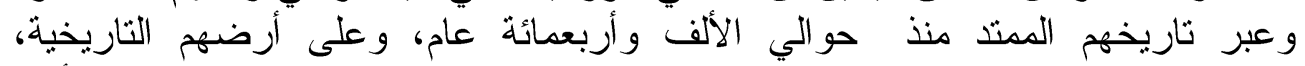

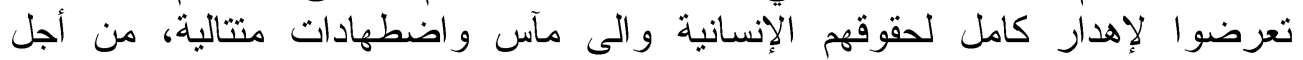

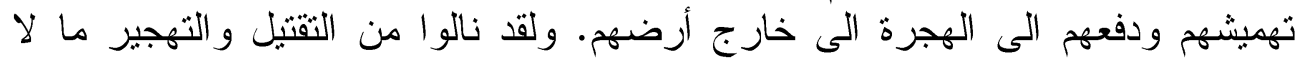

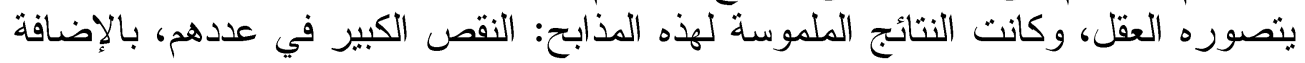

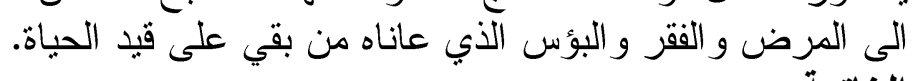

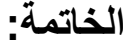

عرض البحث قضية مهمة تتعلق بقضايا حقوق الإنسان، وهي قضية اضطهاد

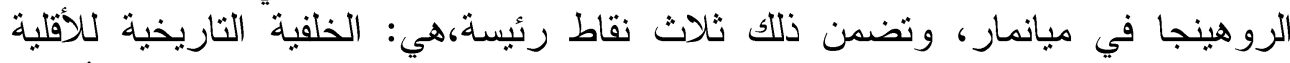

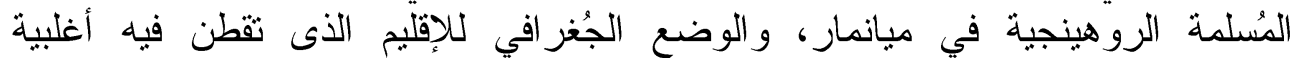

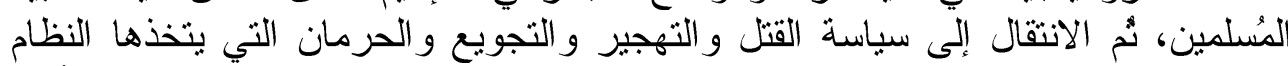

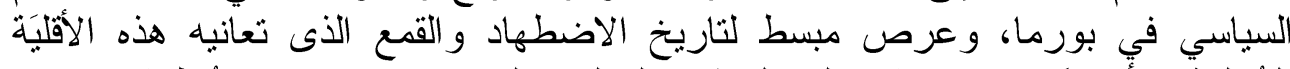

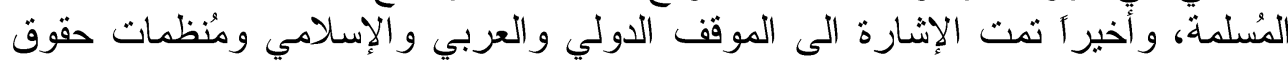
الانسان العالمية تجاه قضية الروهينجا المضطهدة في بورما. 


\section{Abstract}

The Burmese Aggressions on the Rohingya Muslim in Burma "Myanmar" and the International Arab Muslim Stance them (1948 - 2012)

\section{By Maison Mansour}

The research aims to introduce the reader to the most important attacks and violations against the Myanmar Rohingya minority, and its causes and consequences, both at the level of Muslim minorities and the level of the Muslim world, and to present the history of this Muslim minority in Burma. It also addressed a number of problems faced by this minority, such as the problems of restricting them in the exercise of their rituals, discrimination at work, problems of education, integration, identity theft, language problems, psychological suffering and alienation. And the most important solutions to curb this dangerous phenomenon, and ended the research to a number of conclusions and recommendations, the most important of which is that "supporting these minorities is a legitimate duty first, which is the first line of defense for Islam wherever it exists.

) إسلام عبد التواب، الأقليات المسلمة في المجتمعات غير الإسلامية، بحث مقدم إلى مؤتمر مكة

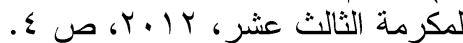

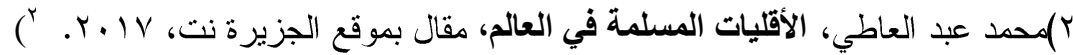

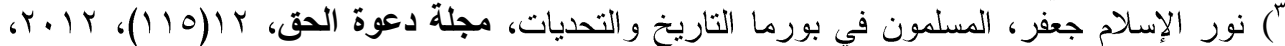

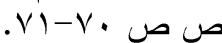
") محمد حسن بكر ، مختصر تاريخ المسلمين في أراكان بورما، طا، دار المجد للطباعة و النشر، عمان، .

•)CIA, "The Facts," CIA Report, Washington, 2016, p. 5.

) الباتان: الباتان جماعة يقطن أكثر هم في باكستان و أفغانستان و الهند، ويعرفون أيضا بالبشتون.

צاجوناثان هيد، المسلمون المهجرون والمشتتون بميانمار، وكالة أنباء أراكان ANA ، كارس،

. $r$. I $\leqslant$

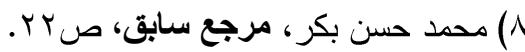

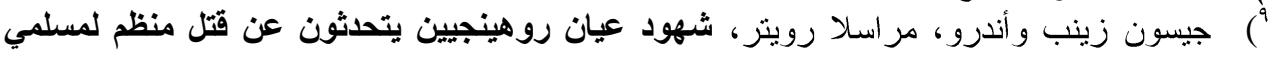

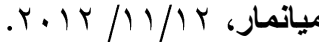

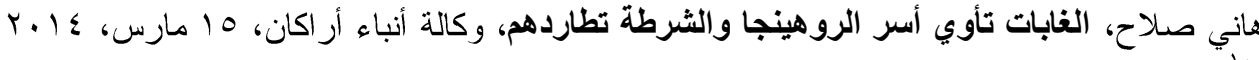

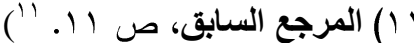

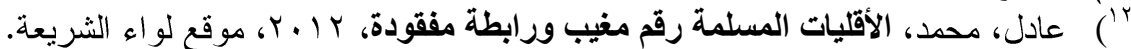

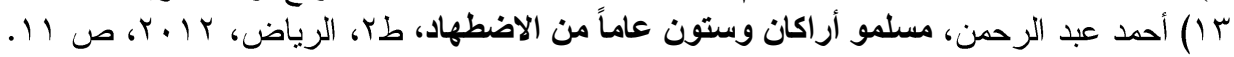

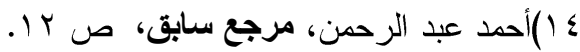

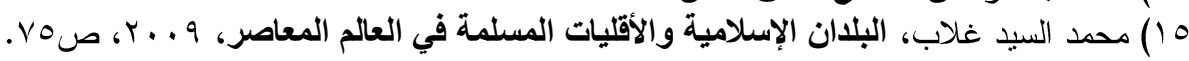

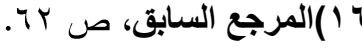




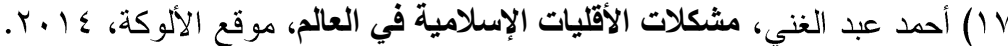

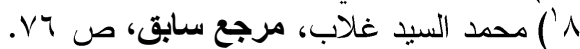

9 (1) جريدة اللواء، السعودية، عمليات القمع والإبادة المستمرة بحق الروهينجا، تاريخ النشر: بr تموز ، .$Y \cdot 17$

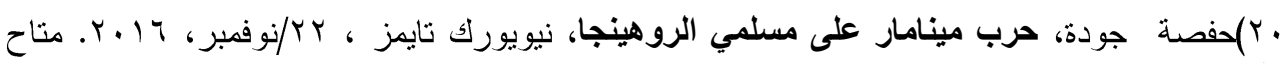

https://www.noonpost.org/content/15199

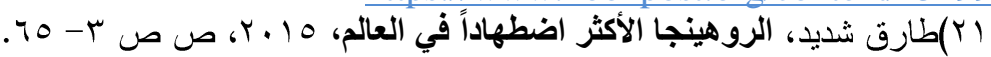

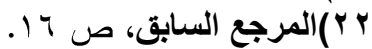

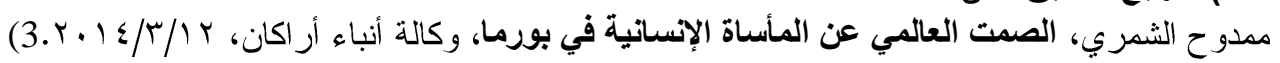

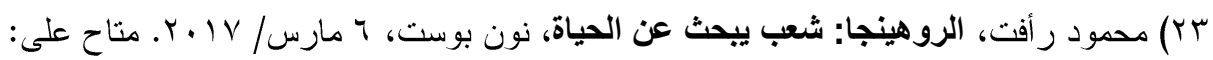
https://www.noonpost.org/content/16927

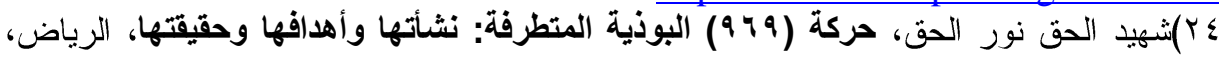

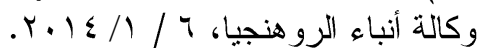

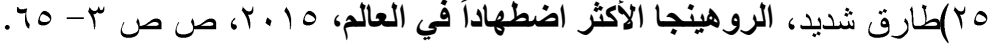

بr/نادية محمود مصطفى، أنماط الأقليات والمعايير والمشاكل للاقّليات المسلمة، شبكة إسلام أون لاين،

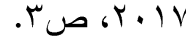

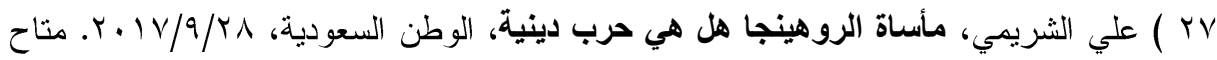

على: http://elaph.com/Web/NewsPapers

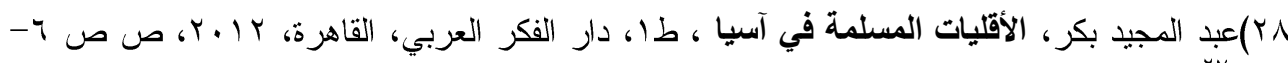

29) Manu Tin, G. H. Luce, the Glass Palace Chronicle of the Kings of

Burma, 2012, University Press, Rangoon. • آم) الأمم المتحدة، وثائق الأمم المتحدة والمواثيق والاتفاقيات الاولية الخاصة بحقوق الإنسان، موقع

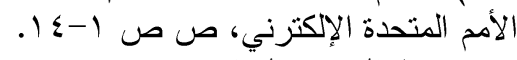

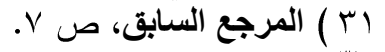

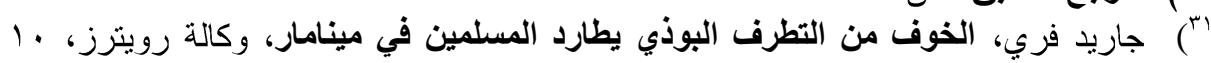

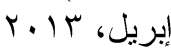
(البريل، لألأمم المتحدة، وثثائق الأمم المتحدة والمواثيق والاتفاقيات الدولية الخاصة بحقوق الإنسان،

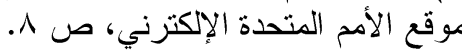

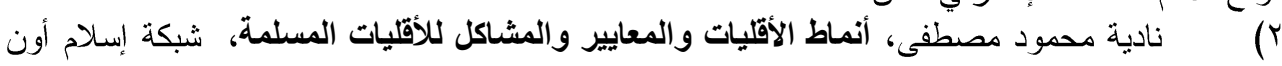

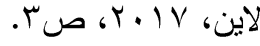

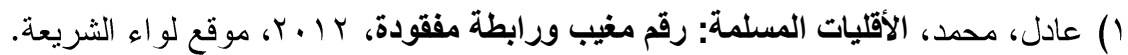

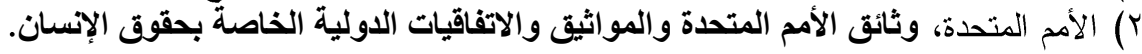




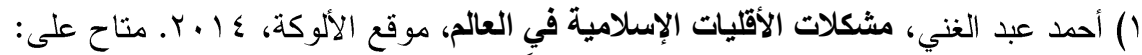

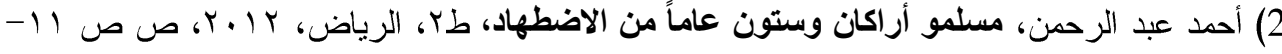
3) إسلام عبد التواب، الأقليات المسلمة في المجتمعات غير الإسلامية، بحث مقدم إلى مؤتمر مكة

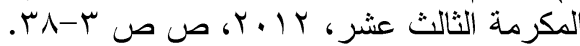
4) الأمم المتحدة، وثثائق الأمم المتحدة والمواثيق والاتفاقيات الدولية الخاصة بحقوق الإنسان، موقع الأمم

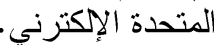
5) جريدة اللو اء، السعودية، عمليات القمع والإبادة المستمرة بحق الروهينجا، تاريخ النشر : بr /V، $.4 \cdot 14$

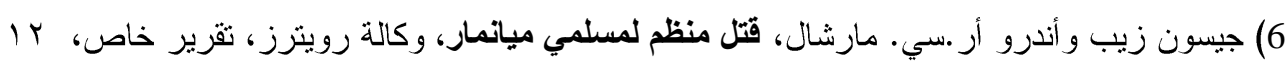

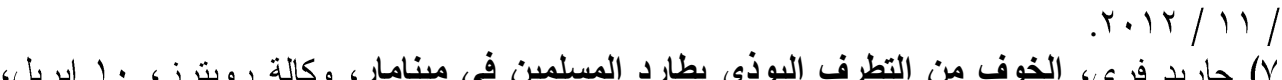

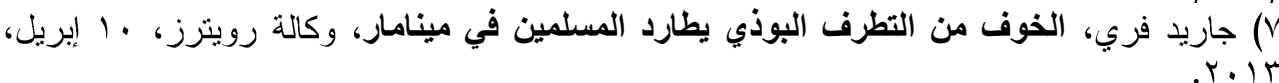
^) جوناثان هيد، المسلمون المهجرون والمشتتون بميانمار، وكالة أنباء أراكان ANA ،ه مارس، $. r+1 \varepsilon$

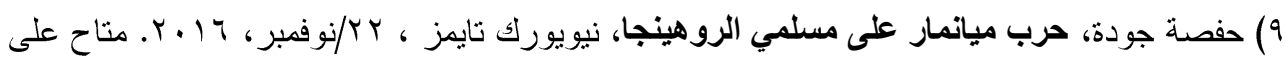
https://www.noonpost.org/content/15199

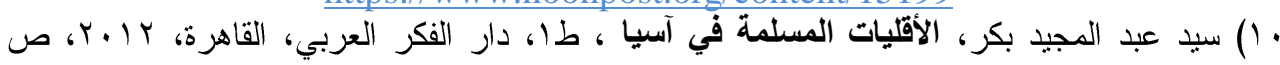
11) شهيد الحق، حركة (1979 (19) البوذية المتطرفة: نثأتها وأهدافها وحقيقتها، الرياض، وكالة أنباء

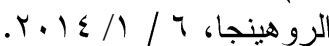

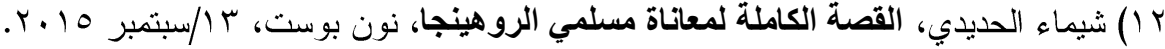
https://www.noonpost.org

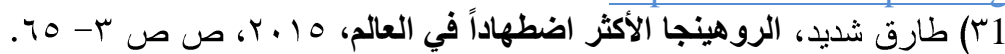

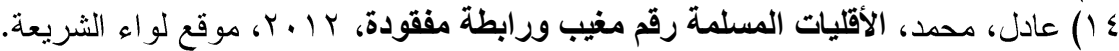

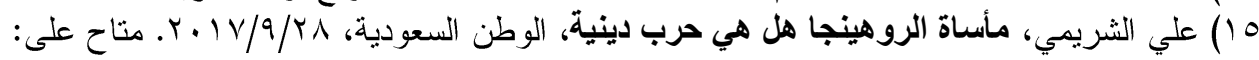
http://elaph.com/Web/NewsPapers/2017/9/1169515.htm 17) محمد حسن بكر، مختصر تاريخ المبلمين في أراكان بورما، طا، دار المجد للطباعة و النشر،

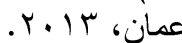

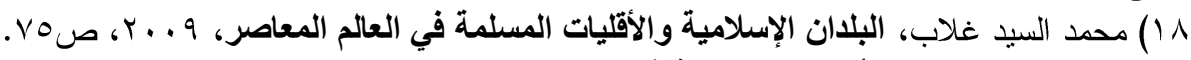

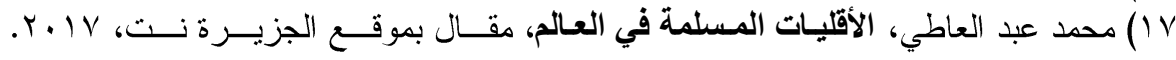

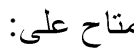
http://www.aljazeera.net/specialfiles/pages/fa45fbf5-7985

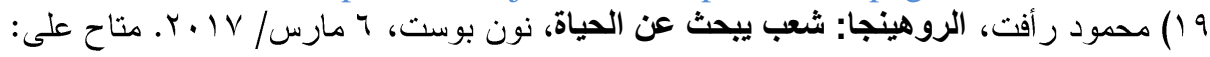
https://www.noonpost.org/content/16927

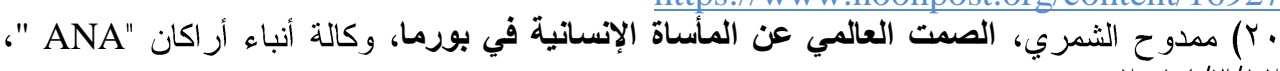
$. r \cdot 1 \varepsilon / r / T$ r) نادية محمود مصطفى، أنماط الأقليات والمعايير والمشاكل للأقلّات المسلمة، شبكة إسلام أون لاين، 
net.islamonline.mdarik متاح على:

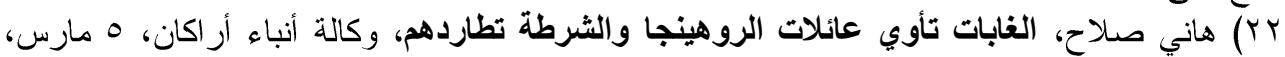

CIA, The Facts, CIA Report, Washington, 2016, p 5.r

24 ) Muthieu Smith, Religious Persecution in Burma State Policy, The Wall Street Journal, February 20, 2014.

24 ) Manu Tin, G. H. Luce, the Glass Palace Chronicle of the Kings of Burma 2012, University Press, Rangoon . 